\title{
Using Microporous Polytetrafluoroethylene Thin Sheets as a Flexible Solar Diffuser to Minimize Sunlight Glint to Cameras in Space \\ Michael K. Choi*a \\ ${ }^{a}$ NASA Goddard Space Flight Center, Greenbelt, MD 20771, USA
}

\begin{abstract}
An innovative design of using microporous PTFE thin sheets as a solar diffuser for MLI blankets or mechanical structure has been developed. It minimizes sunlight or stray-light glint to cameras when it is incident on these components in space. A microporous black PTFE thin sheet solar diffuser has been qualified for flight at NASA GSFC and installed to the TAGSAM arm MLI, OCAMS PolyCam sunshade MLI and SamCam motor riser MLI in the NASA OSIRIS-REx mission to meet the SamCam camera BRDF requirement.
\end{abstract}

Keywords: microporous PTFE, flexible solar diffuser, stray-light, diffuse, glint, black PTFE, white PTFE, MLI cover

\section{INTRODUCTION}

The NASA Origins, Spectral Interpretation, Resource Identification, Security, Regolith Explorer (OSIRIS-REx) spacecraft will travel to a near-Earth asteroid (101955) Bennu, study it in detail, and bring back a pristine sample to Earth for scientific analyses. Figure 1 is an artist's impression of the asteroid (101955) Bennu. The Touch And Go Sample Acquisition Mechanism (TAGSAM), which has an arm, motors, frangibolts and sampler head, collects samples. Touch And Go (TAG) occurs at 0.9 to 1.4 astronomical unit (AU). Figure 2 shows an artist's impression of OSIRISREx, with the TAGSAM deployed for TAG. During TAG, the TAGSAM is exposed to the sun continuously for as much as 5 days. The TAGSAM arm is insulated with multilayer insulation (MLI) blankets from the extreme thermal environments in flight.

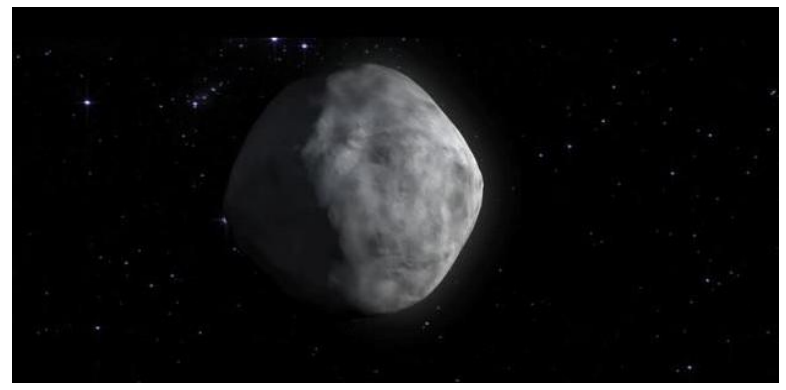

Figure 1. Artist's Impression of Asteroid (101955) Bennu (Source: NASA GSFC).

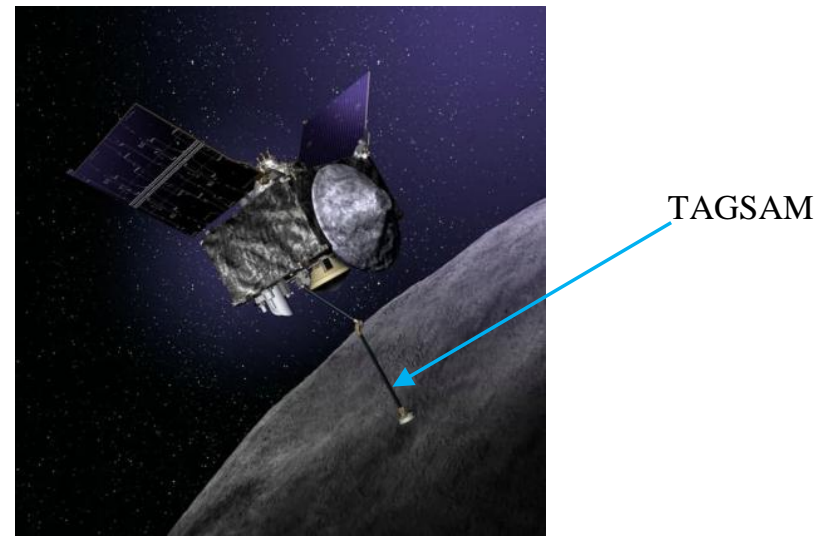

Figure 2. Artist's Impression of OSIRIS-REx During TAG at Asteroid (101955) Bennu (Source: OSIRIS-REx Project). 
The stowed TAGSAM on the OSIRIS-REx spacecraft is shown in Figure 3. During TAG, SamCam, which is one of the three cameras of the OSIRIS-REx camera suite (OCAMS), will continuously document the sample acquisitions. Figure 4 and Figure 5 show the SamCam field of view (FOV) during sampling and sample imaging respectively. ${ }^{1,2}$ PolyCam and MapCam are the other two cameras of the OCAMS. The OCAMS cameras are mounted to the payload deck by using titanium flexures. They are also shown on Figure 3. If the TAGSAM MLI outer cover, specifically on and around the nitrogen bottles, is specular, it will lead to sunlight glint to the SamCam during TAG and blind the camera. Two other locations also have glint issues: a) the PolyCam sunshade MLI which reflects stray light into the MapCam during the dust-plume survey because stray light would look the same as a dust plume, b) the SamCam motor riser MLI at low sun incidence angles because stray light can be reflected into the SamCam.

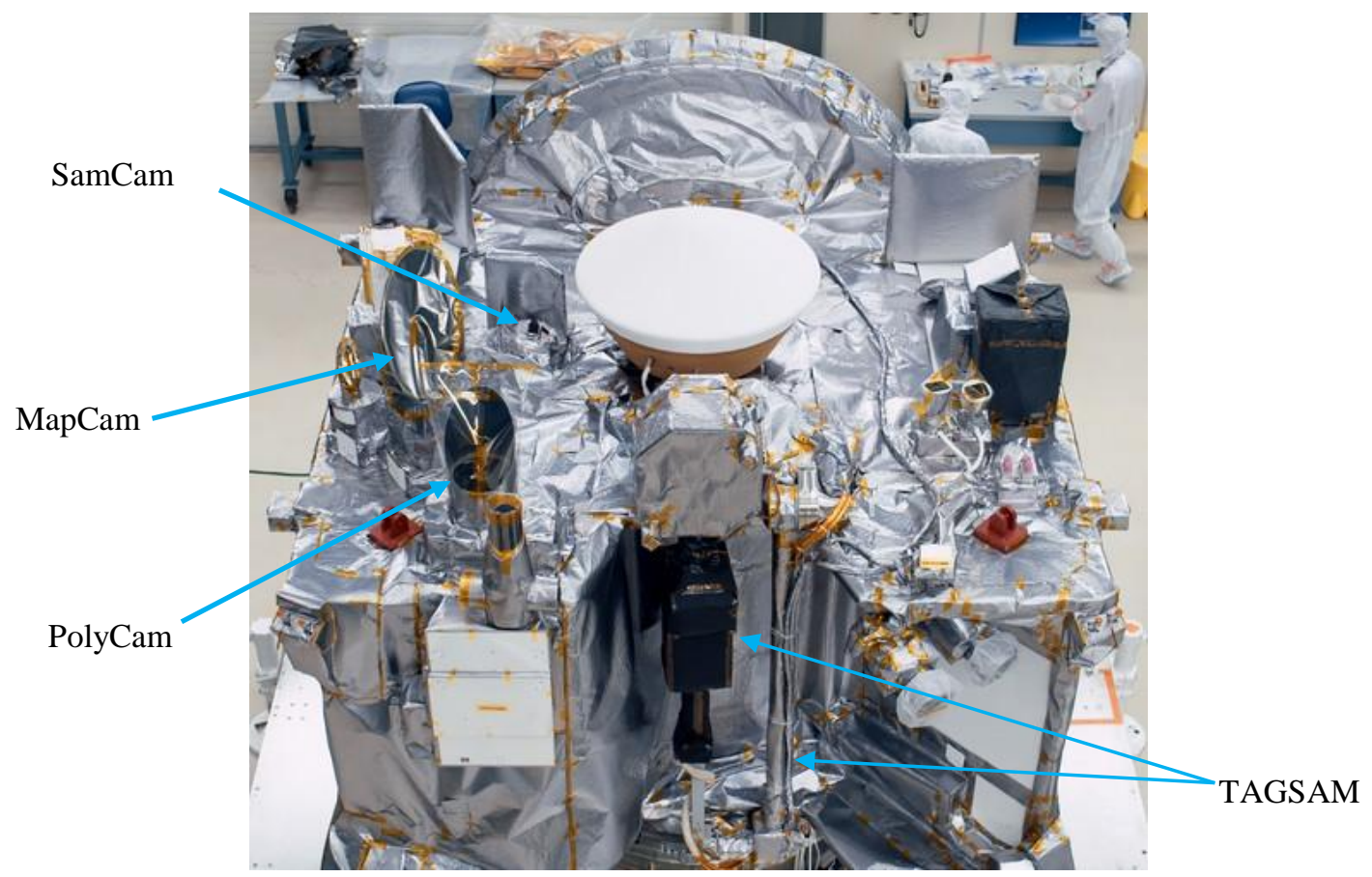

Figure 3. OCAMS and TAGSAM on OSIRIS-REx Spacecraft (Source: OSIRIS-REx Project).

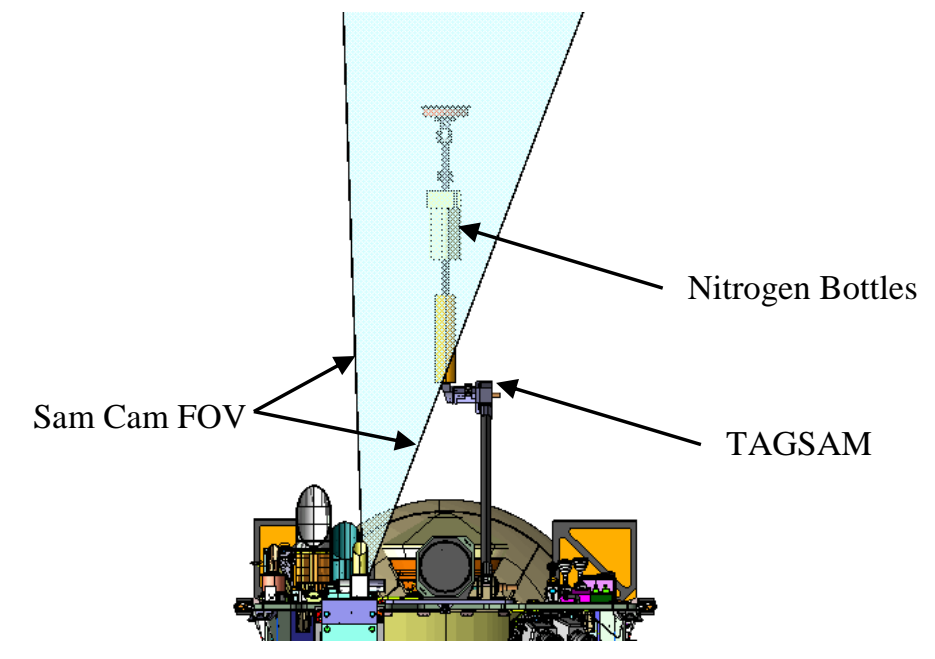

Figure 4. SamCam FOV During Sampling. 


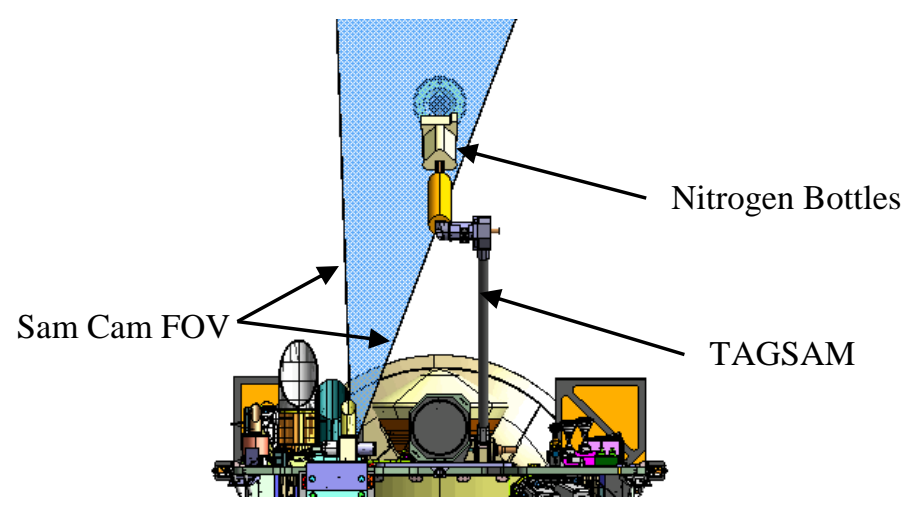

Figure 5. SamCam FOV During Sample Imaging.

Figure 6 shows the possible sun angles with respect to the spacecraft coordinate system and asteroid latitude for TAG to occur, for example, at 1.333 AU on August 24, 2019. ${ }^{3}$

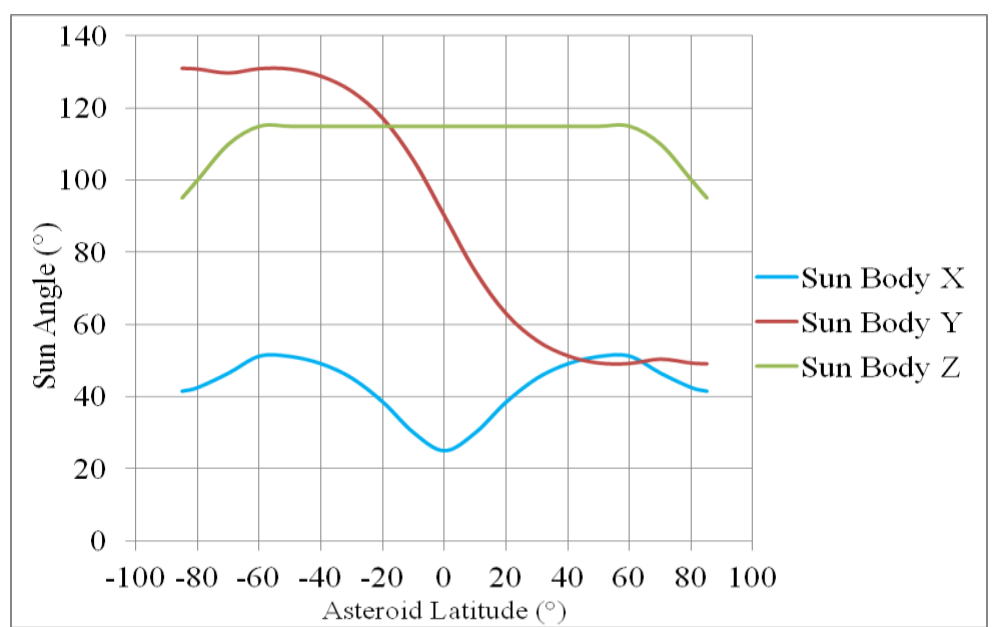

Figure 6. Sun Angles With Respect To Spacecraft Coordinate System and Asteroid Latitude.

The OCAMS instrument team performed radiometric calculations to derive the following for the SamCam. ${ }^{4} \mathrm{Up}$ to $\pm 65^{\circ}$ asteroid latitudes, an irradiance greater than $6.8 \times 10^{-5} \mathrm{~W} / \mathrm{mm}^{2}\left(4.5 \times 10^{-9} \mathrm{~W} /\right.$ pixel $)$ will result in blooming. At $\pm 85^{\circ}$ asteroid latitudes, irradiance greater than $1.2 \times 10^{-5} \mathrm{~W} / \mathrm{mm}^{2}\left(8.7 \times 10^{-10} \mathrm{~W} / \mathrm{pixel}\right)$ will result in blooming. Also the OCAMS team's glint analysis for SamCam was done for a $65^{\circ}$ phase angle, corresponding to $\pm 65^{\circ}$ asteroid latitude (Figures 7 and 8). ${ }^{5}$ Hence the requirement is that the irradiance at each pixel must not exceed $6.8 \times 10^{-5} \mathrm{~W} / \mathrm{mm}^{2}$.

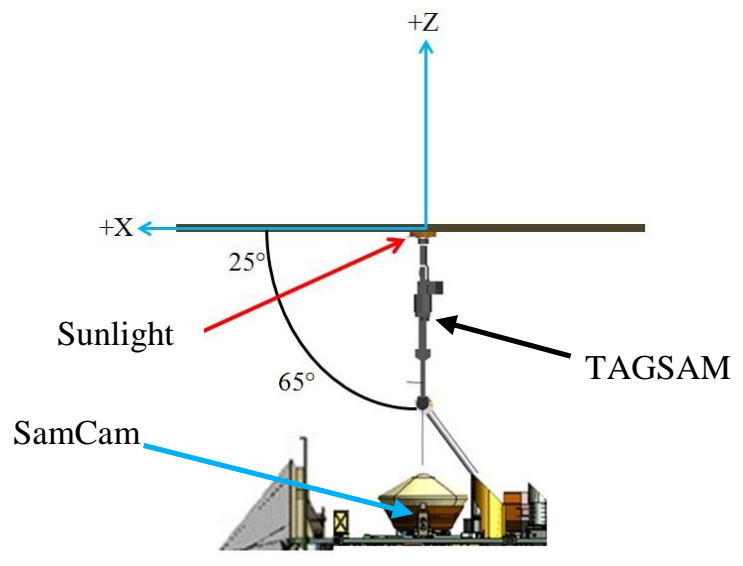

Figure 7. Sun Angle During TAG for Asteroid Latitudes Between $-65^{\circ}$ and $+65^{\circ} .^{3}$ 


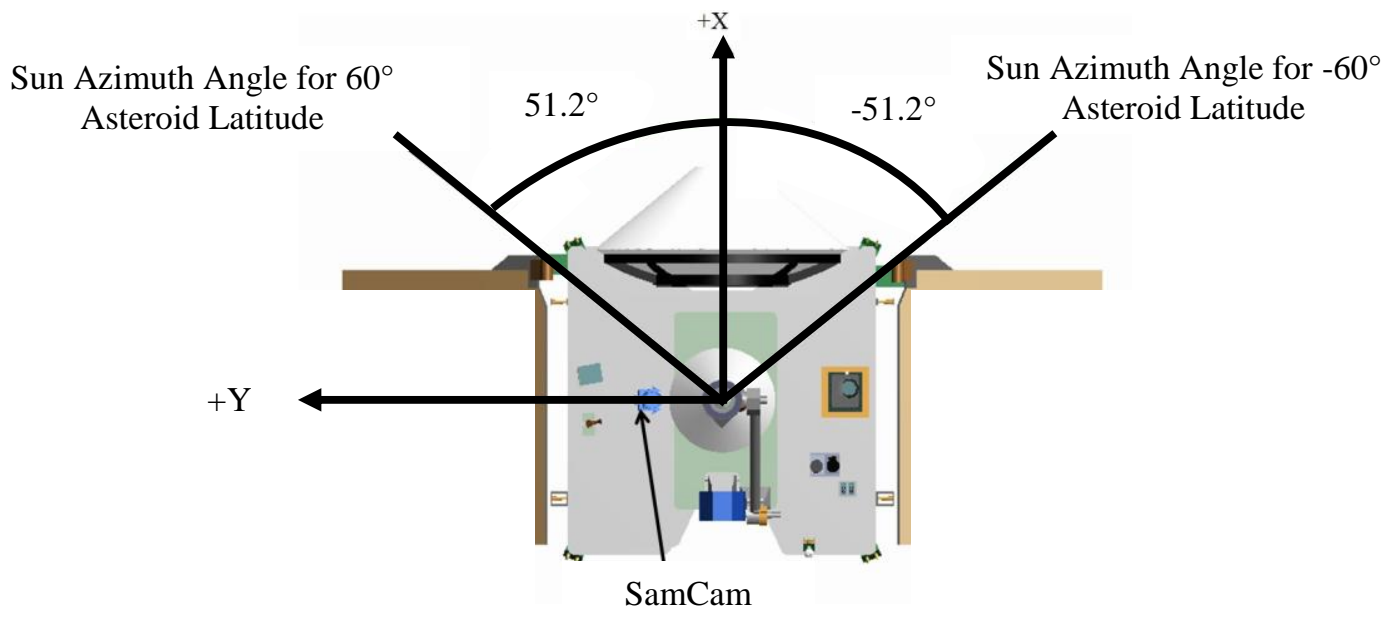

Figure 8. Sun Angle Azimuth Range and Asteroid Latitude During TAG. ${ }^{3}$

Figure 9 shows an approximate view of TAGSAM from SamCam during TAG. Optical analysis showed that a diffuse black coating or material is required for MLI blankets on and around the TAGSAM arm nitrogen bottles. ${ }^{5}$

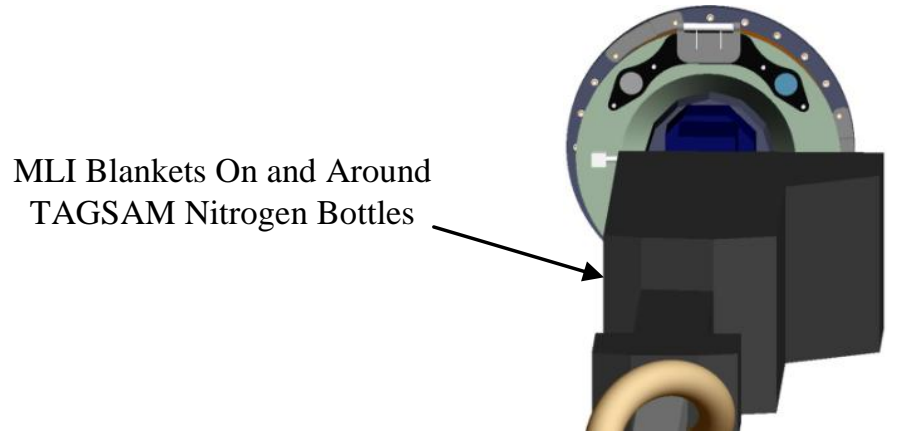

Figure 9. Approximate View of TAGSAM from SamCam During TAG.

\section{REQUIREMENTS}

There are several requirements, related to stray-light glint on the SamCam, that are difficult to meet:

-Bidirectional reflectance distribution function (BRDF): Not to exceed $0.32 \mathrm{sr}^{-1}$ from $0^{\circ}$ to $50^{\circ}$ incidence angle.

-Contamination: No free carbon is allowed for MLI blankets, unless it meets Level $100 \mathrm{~A} / 2$ non-volatile residue cleanliness levels requirement.

-Temperature: MLI blanket outer cover must survive a long-term exposure to sunlight at 0.897 astronomical unit (AU) during TAG.

-Workability: MLI blanket outer cover must be flexible and able to be bent, folded, incorporated into MLI, handled during ATLO, etc., without shedding particles and/or losing desired optical properties.

-Surface resistivity: MLI blanket outer cover on the TAGSAM must be conductive to minimize the risk of electrostatic discharge, or adequately grounded if it is not conductive.

\section{WHY MICROPOROUS PTFE?}

\subsection{Issue with Specular Films}

All the MLI blanket outer cover materials commercially available today have high solar specularity. Kapton, black Kapton, Germanium black Kapton, StaMet black Kapton, aluminum tape, and aluminum are all bright when they are exposed to the sun (Figure 10). Black Kapton has a high solar absorptance, but its solar specularity is also high. BRDF measurement on black Kapton showed that it does not meet the SamCam BRDF requirement (Figure 11). ${ }^{5}$ 


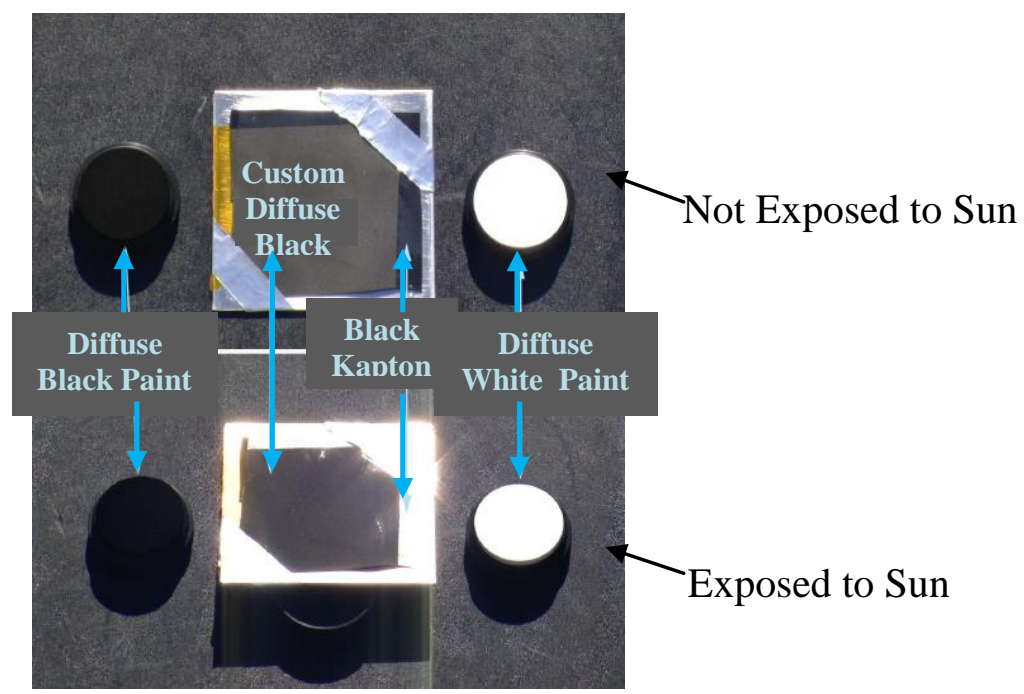

Figure 10. Brightness of Coatings When Exposed to Sun (Credit: OSIRIS-REx Project).

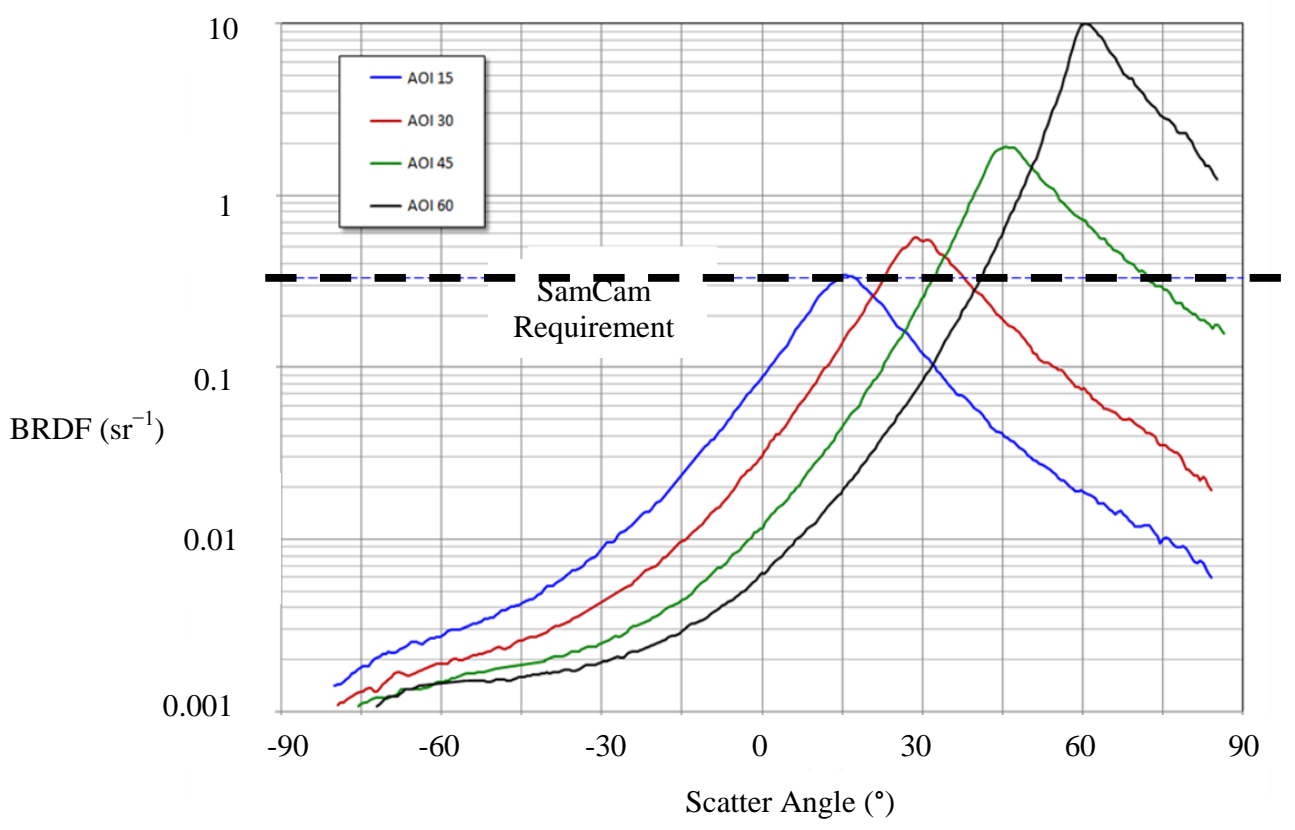

Figure 11. BRDF of Black Kapton at 514 nm (Credit: OSIRIS-REx Project).

\subsection{Issue with Temperature}

During TAG, the TAGSAM MLI blankets will have a long-term exposure to sunlight at 0.897 AU. The solar irradiance is $1,724 \mathrm{~W} / \mathrm{m}^{2}$. The maximum predicted temperature of MLI outer cover with black and diffuse materials is $153^{\circ} \mathrm{C}$, assuming an absorptance of 0.96 and a hemispherical emittance of 0.89 , and it is adiabatic. After adding a $10^{\circ} \mathrm{C}$ thermal design margin, the MLI blanket outer cover bakeout temperature to meet the mission contamination control requirement is $163^{\circ} \mathrm{C}$. The material must survival such a high temperature. The PolyCam sunshade MLI also has long-term exposure to sunlight at $0.773 \mathrm{AU}$ to $1.39 \mathrm{AU}$ in other mission phases. At $0.773 \mathrm{AU}$ in the hot cruise mission phase, the solar irradiance is $2,322 \mathrm{~W} / \mathrm{m}^{2}$. The PolyCam sunshade is not adiabatic since the sunshade structure is a scarf cylinder which is painted black on the interior. The black interior radiates heat to deep space through the aperture. Heat leaks from the 
sunside through the MLI to the black interior by radiation. The microporous black PTFE maximum flight temperature prediction is warmer than but close to the $163^{\circ} \mathrm{C}$ bakeout temperature.

Custom diffuse black Kapton was developed at Goddard Space Flight Center (GSFC) for the OSIRIS-REx Project. It is not bright when exposed to the sun (Figure 10). It met the SamCam BRDF requirement with adequate margins. Its constituents include LORD Aeroglaze ${ }^{\circledR}$ Z307 black paint. Baking out diffuse black Kapton at a combination of high temperature and long time ( 149 hours at $163^{\circ} \mathrm{C}$ and 54 hours at $130^{\circ} \mathrm{C}$ to $\left.163^{\circ} \mathrm{C}\right)$ to meet the mission contamination control requirement led to paint flaking problems. Options to replace custom diffuse black Kapton were evaluated.

\subsection{Objective}

This paper presents an innovative design which uses commercially available microporous polytetrafluoroethylene (PTFE) thin sheets as a solar diffuser for MLI outer covers or mechanical structure for space flight, and to satisfy the OSIRIS-REx requirements related to the SamCam. The sheets are $0.25 \mathrm{~mm}(10 \mathrm{mil})$ thick, flexible, bendable and lightweight. They can be attached to the MLI blanket outer cover or mechanical structure by using a low outgas transfer adhesive or epoxy.

\subsection{Overview of Microporous PTFE Lambertian Diffuser ${ }^{6-16}$}

PTFE is commercially available in two forms for optical applications: a) high density (solid), b) low density (microporous) sintered. The microporous network of the latter provides multiple solar reflections when sunlight is incident on it. Microporous sintered PTFE has an extremely high diffuse reflectance in the ultraviolet (UV) to near infrared (NIR) spectral region and behaves as a Lambertian diffuser. It is stable indefinitely under normal conditions. Advanced aging studies on sintered PTFE have revealed that it has a stability more than 100 years. Its instability is only caused by contaminants introduced from the its environment. Extensive research has shown that UV radiation above 350 $\mathrm{nm}$ has little, if any, effect on sintered PTFE materials if they are kept clean. Volatile contaminants can be removed by vacuum bakeout at temperatures higher than $90^{\circ} \mathrm{C}$. Expansion and contraction of the material, due to temperature changes, may cause minor changes in its reflectance. No literature citations indicate such effect. Stable properties of microporous sintered PTFE in the UV to NIR spectral range make it attractive in many radiometric applications, such as measuring heads for spectroradiometers and broadband radiometers. ${ }^{6}$ Sintered space grade PTFE diffusers are commercially available, and have been used extensively as a standard for spectrophotometers and spectroradiometers on spacecraft in low Earth orbit. Examples are NASA's Moderate Resolution Imaging Spectroradiometer (MODIS) and Visible Infrared Imaging Radiometer Suite (VIIRS), and ESA's Medium Resolution Imaging Spectrometer (MERIS). Space grade Spectralon ${ }^{\mathrm{TM}}$ is the most commonly used reflectance standard in space applications. The operating temperature range of microporous PTFE is $-260^{\circ} \mathrm{C}$ to $260^{\circ} \mathrm{C}$. Grey scale diffusers and sintered PTFE doped with black pigments, are commercially available but have not been flown on spacecraft. Depending on the BRDF requirement for the optical systems, black or white microporous PTFE can be used. The white version is pure PTFE, and electrically non-conductive. The black version has carbon black embedded in the PTFE, and is electrically conductive. It has a much better BRDF than the white version, but is much hotter when exposed to sunlight. Flexible microporous PTFE sheets, to be used as MLI blanket cover in the OSIRIS-REx mission, must not exceed $0.254 \mathrm{~mm}$ (10-mil) thick. For such a small thickness, optical properties of white PTFE are strongly dependent on the size of micropores. Figure 12 shows such microporous black PTFE and microporous white PTFE samples in the sun, with vacuum deposited aluminum (VDA) as the substrate for a contrast.

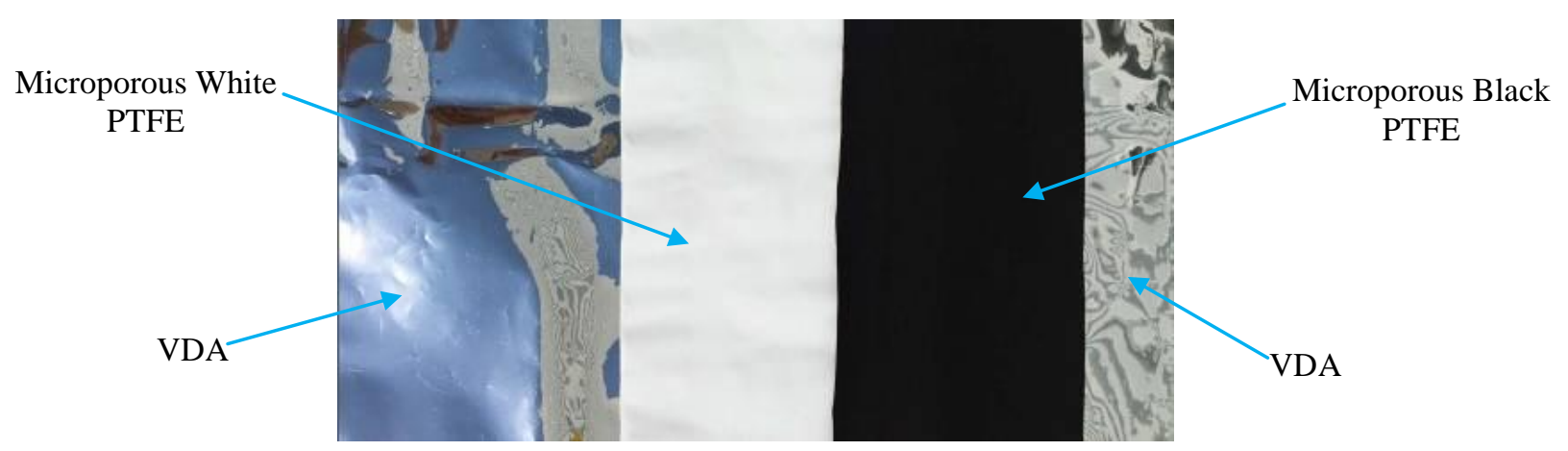

Figure 12. Microporous Black PTFE, Microporous White PTFE and VDA Exposed to Sun. 


\section{CHEMICAL ANALYSIS ON MICROPOROUS PTFE}

Black and white microporous PTFE samples were sent to NASA Johnson Space Center for chemical analysis. The texture, composition and propensity for particulate shedding were examined by using Microprobe Two-Step Laser Mass Spectrometry $\left(\mu-\mathrm{L}^{2} \mathrm{MS}\right.$ ) and Field Emission Scanning Electron Microscopy (FESEM) / Energy Dispersive Spectrometry (EDX). ${ }^{17}$ The white PTFE samples have different micropore sizes. The results confirmed that a) the microporous white PTFE samples are 100\% PTFE, b) the microporous black PTFE sample contains separate PTFE and carbon black, c) the microporous black PTFE sample has a complex distribution of organic species with a mass ranging extending beyond $500 \mathrm{Da}$. An organic analysis of microporous white PTFE samples by using $\mu-\mathrm{L}^{2} \mathrm{MS}$ showed the composition of laser desorbable organic species to be almost exclusively composed of the PTFE monomer $\mathrm{C}_{2} \mathrm{~F}_{4}$, with trace amounts of low molecular weight hydrocarbons associated with superficial surface adsorption from the ambient environment. The mass envelope of microporous black PTFE sample is typical of that shown by carbon black particulates which are generally used to make black finishes. Figure 13 and Figure 14 show the results of chemical analysis of the microporous white PTFE sample and black PTFE sample respectively. ${ }^{17}$

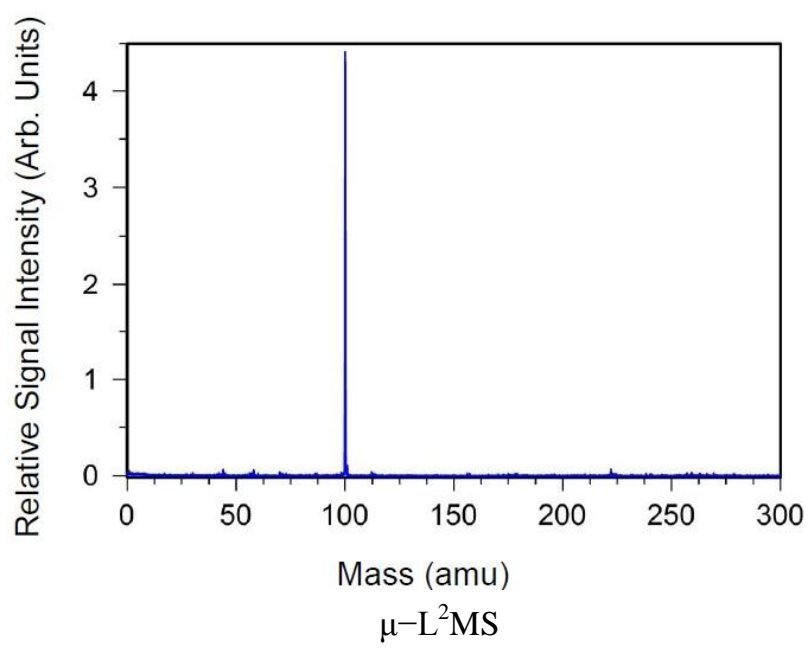

Figure 13. Microporous White PTFE Chemical Analysis Results .

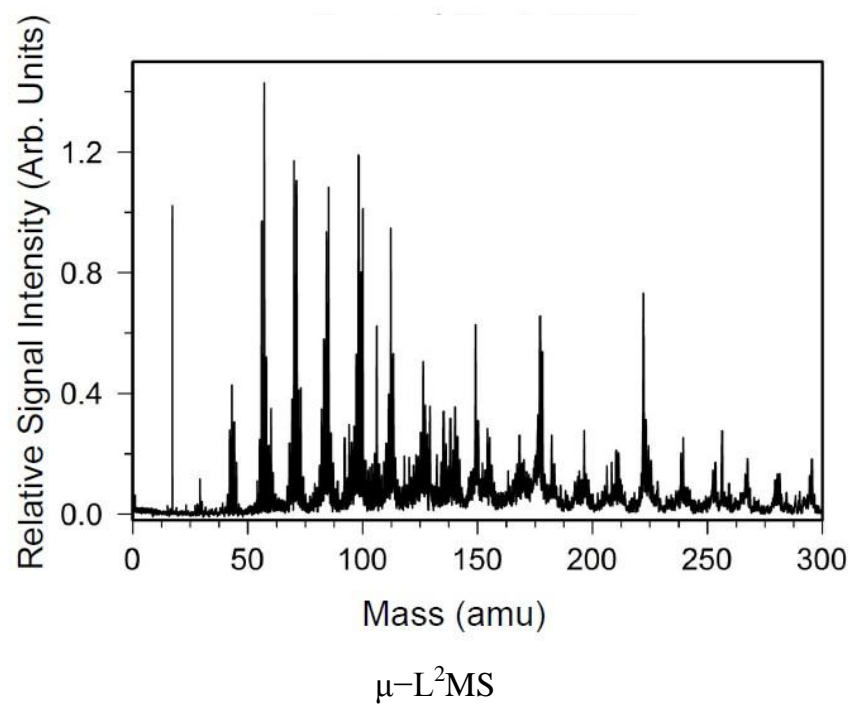

Figure 14. Microporous Black PTFE Chemical Analysis Results .

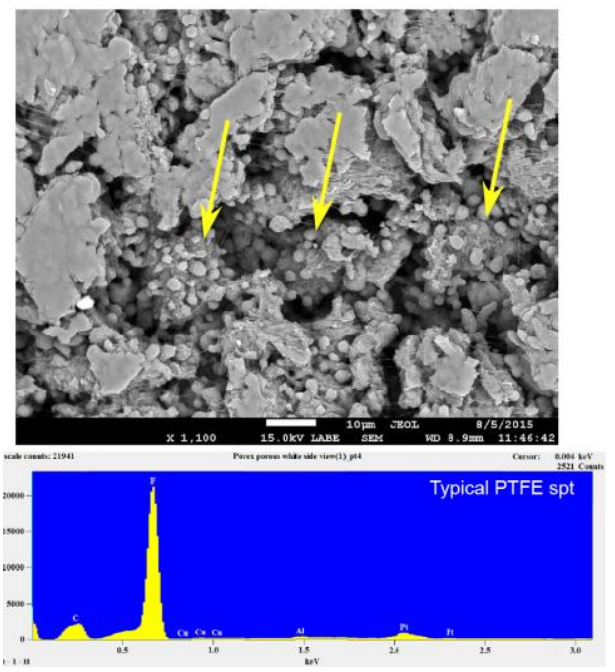

FESEM (Top) / EDX (Bottom)

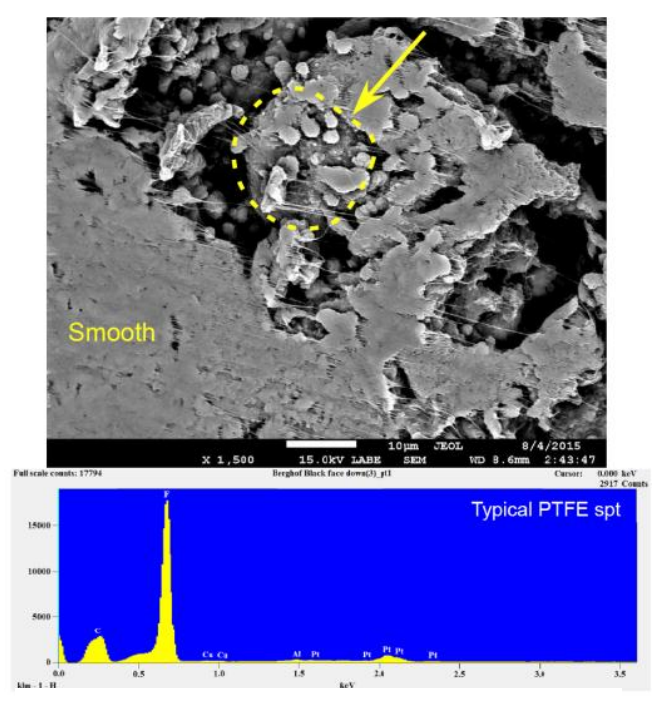

FESEM (Top) / EDX (Bottom) 


\section{TESTING ON MICROPOROUS PTFE}

\subsection{Thermal Vacuum Cycling on Microporous PTFE Samples}

A thermal vacuum cycling test on microporous PTFE samples was performed for the OSIRIS-REx mission at GSFC. A sample of microporous black PTFE and three samples of microporous white PTFE were attached by an acrylic transfer adhesive to a MLI blanket. The MLI had a black Kapton outer cover to simulate the flight MLI on the TAGSAM. The microporous white PTFE samples had different pore sizes or thicknesses. The samples faced the vacuum chamber view port so that a solar simulator beam could impinge them during the hot soaks. Figure 15 shows the test samples and MLI blanket in the vacuum chamber. The vacuum chamber shroud was cooled by liquid nitrogen to simulate the deep space temperature. During the hot soaks, the solar simulator beam was turned on to provide 1.5 sun equivalent solar intensity. During the cold soaks, the solar simulator was turned off. A pressure of $1 \times 10^{-6}$ torr was maintained throughout the test.

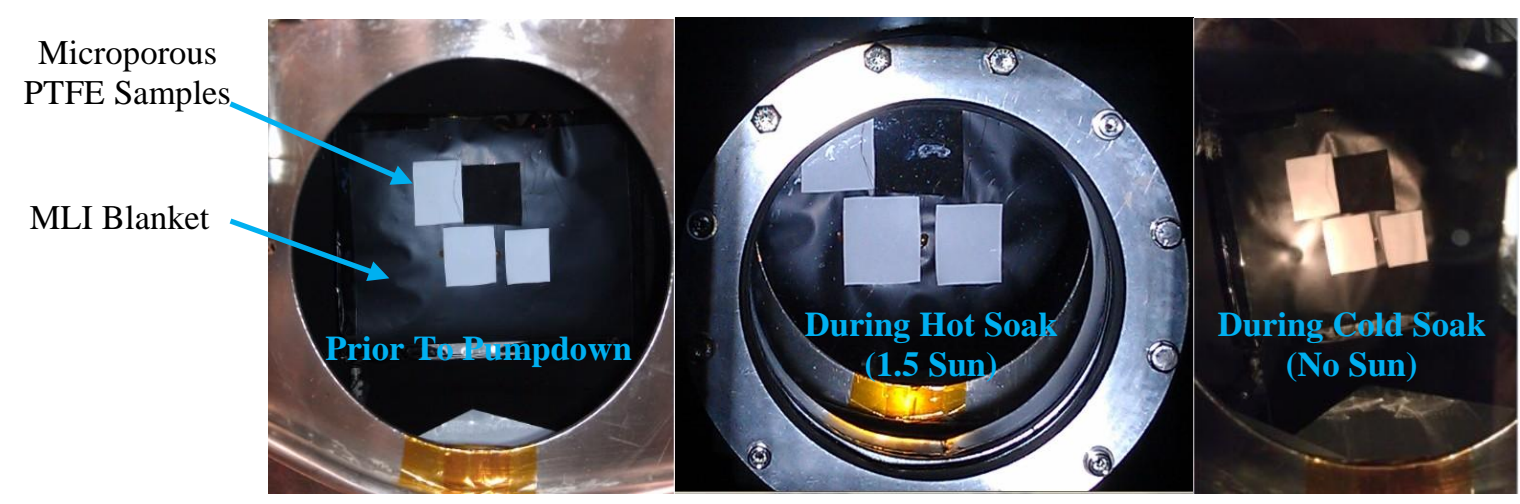

Figure 15. Microporous PTFE Samples in Thermal Vacuum Cycling Test.

Figure 16 presents the temperatures of the microporous PTFE samples in the thermal vacuum cycling test. The average hot soak temperature of the microporous black PTFE sample was $158^{\circ} \mathrm{C}$. The average hot soak temperatures of the microporous white PTFE samples were $85.6^{\circ} \mathrm{C}, 93.9^{\circ} \mathrm{C}$ and $70.4{ }^{\circ} \mathrm{C}$ respectively. The average cold soak temperature of the microporous black PTFE sample was $-124^{\circ} \mathrm{C}$. The average cold soak temperatures of the microporous white PTFE samples were $-125^{\circ} \mathrm{C},-126^{\circ} \mathrm{C}$ and $-127^{\circ} \mathrm{C}$ respectively. After the two thermal vacuum cycles, an exposure to 120 Equivalent Sun Hours (ESH) was added to PTFE samples in vacuum. It increased the total ESH to larger than 200. After the test, the samples were visually inspected. There was no observable difference before and after the test. Also a tape lift test was performed on the samples. No adhesion problem was found.

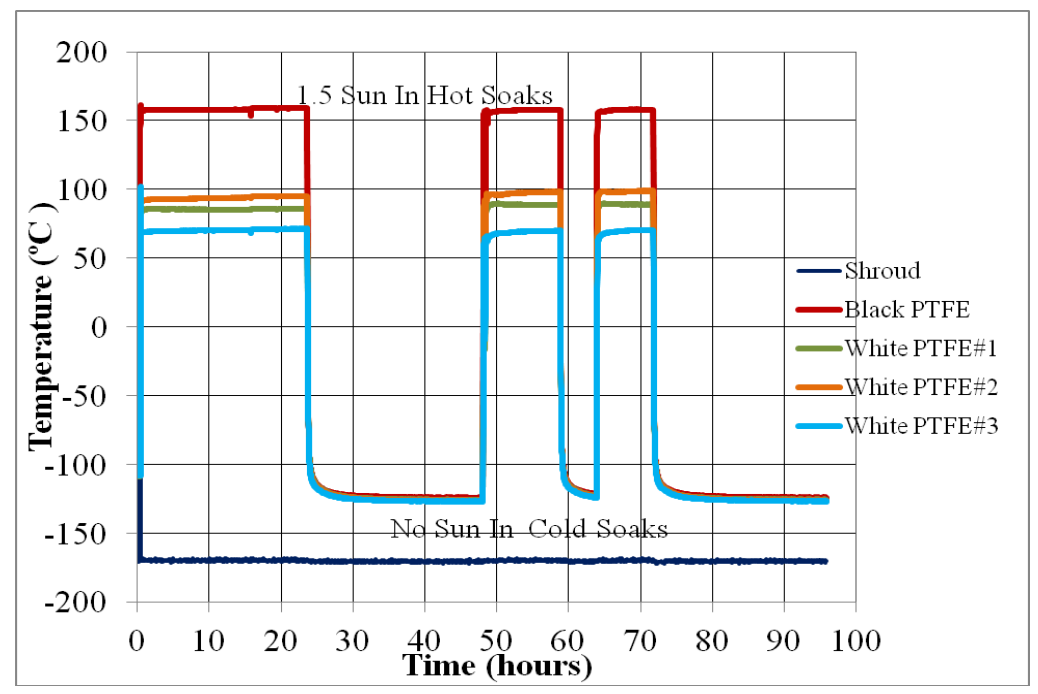

Figure 16. Temperatures of Microporous PTFE Samples in Thermal Vacuum Cycling Test. 
During the thermal vacuum test, the vacuum chamber view port contributed parasitic heat load to the PTFE samples, despite its exterior was covered by a MLI blanket to minimize the effect of ambient air. As a result, the cold soak temperatures of the samples were significantly warmer than the $-171^{\circ} \mathrm{C}$ vacuum chamber shroud temperature. After the thermal vacuum cycling test, the test set-up was re-configured so that the PTFE samples faced the rear of the vacuum chamber shroud. Figure 17 presents the temperatures of the PTFE samples in the 24-hour cold soak. The average temperatures of the samples were below $-160^{\circ} \mathrm{C}$. After the test, the samples were visually inspected. There was no observable difference before and after the test. Also a tape lift test was performed on the samples. No adhesion problem was found.

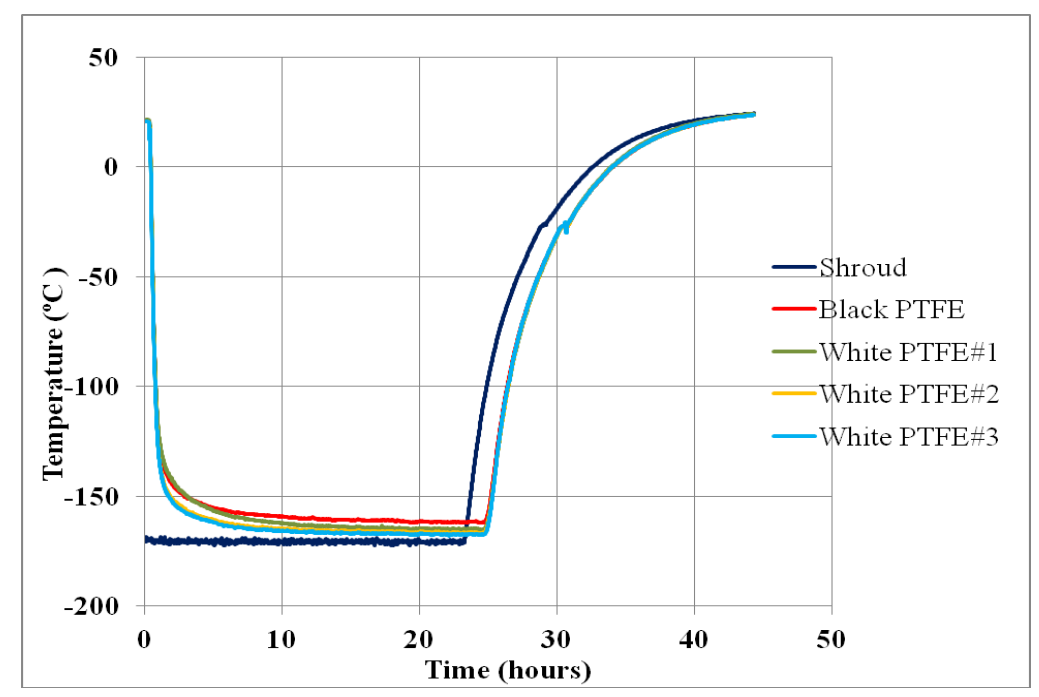

Figure 17. Temperatures of Microporous PTFE Samples in Cold Soak for 24 Hours.

\subsection{Solar Wind Test On Microporous PTFE Samples}

A solar wind test was performed on the microporous PTFE samples to verify the impact of charged particle exposure in flight. The samples used in the test included a) a pristine microporous black PTFE sample from flight batch, b) a pristine microporous white PTFE sample from flight batch, c) a handled/compressed microporous black PTFE sample from flight batch, and d) a handled/compressed microporous white PTFE sample from flight batch. The charged particle exposure in the OSIRIS-REx mission is expected to be:

•Proton energy: $0.835 \mathrm{keV}$.

-Electron energy: $0.455 \mathrm{keV}$.

-Fluence (total dosage through 7 year mission): $\sim 6 \times 10^{16} \mathrm{p} / \mathrm{cm}^{2}$.

In order to make the test time realistic ( $<2$ weeks) and to use the lowest possible energy level in the Solar Wind Facility at GSFC, the following charged particle energy level was used:

-Proton energy: $2 \mathrm{keV}$.

-Electron energy: $0.5 \mathrm{keV}$.

-Fluence (total dosage through 7 year mission): $\sim 6 \times 10^{16} \mathrm{p} / \mathrm{cm}^{2}$.

Figure 18 shows the samples after the test. Figures 19 through 22 present the results of the test. A visual inspection was performed after the test. No visible damage to any sample was observed after test. Microporous black PTFE samples appeared unchanged after test. Microporous white PTFE samples appeared pale brown after test. In-situ measurements of reflectance and solar absorptance showed that a) charged particle exposure had no effect on optical properties of microporous black PTFE (pristine or handled/ compressed), b) charged particle exposure increased the absorptance of microporous white PTFE (pristine or handled/compressed) from 0.085 (at beginning of life (BOL)) to 0.3 (at end of life (EOL)), and decreased its reflectance from 0.9 (at BOL) to 0.2 (at EOL) at $260 \mathrm{~nm}$ wavelength and from 0.9 (at BOL) to 0.7 (at EOL) at $700 \mathrm{~nm}, \mathrm{c}$ ) the microporous white PTFE samples appeared to be more diffuse after test. 


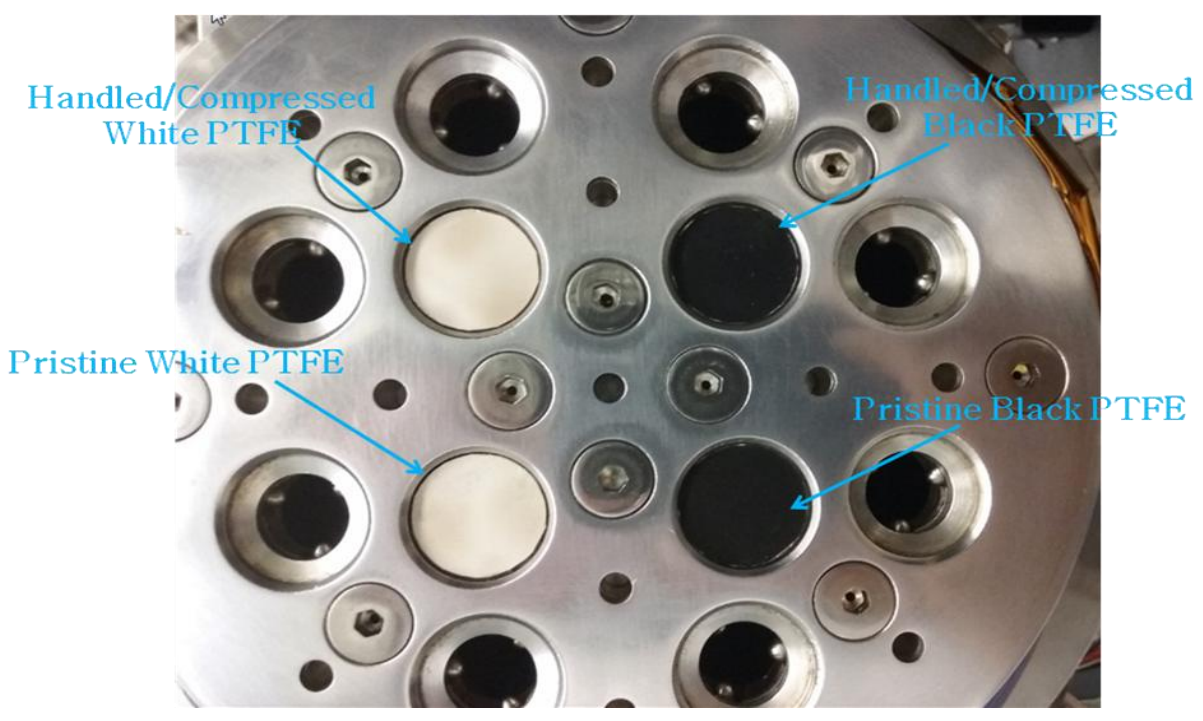

Figure 18. Microporous PTFE Samples After Solar Wind Test.

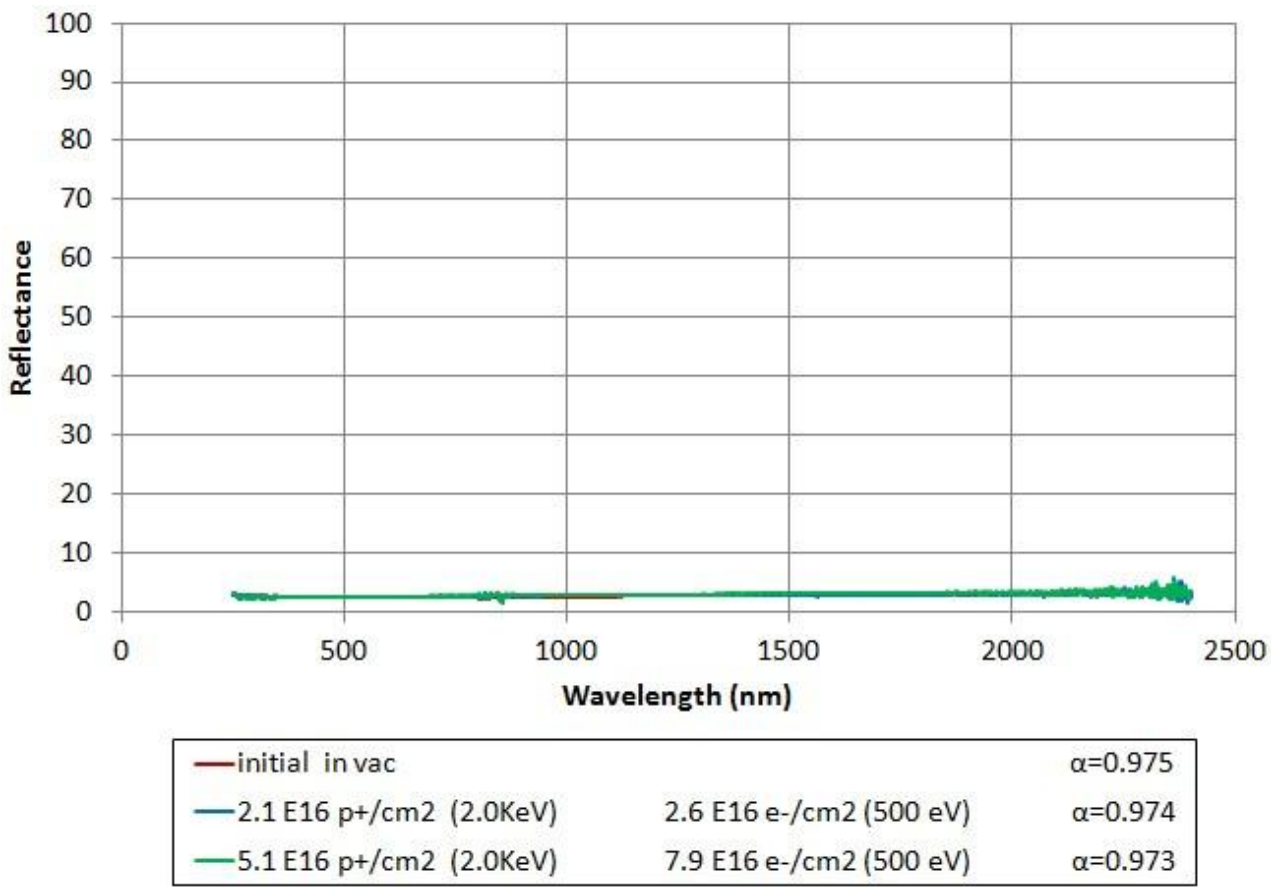

Figure 19. In-Situ Measured Reflectance Versus Wavelength on Microporous Black PTFE. 


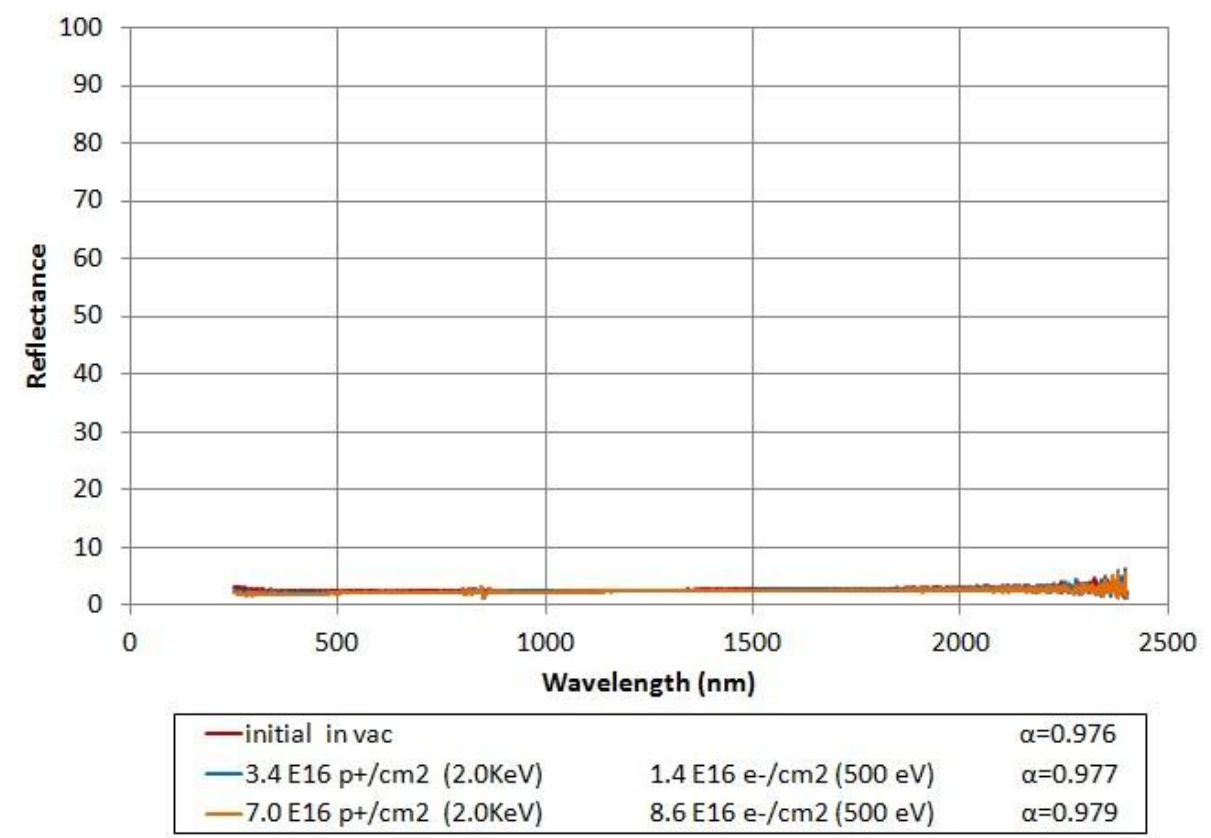

Figure 20. In-Situ Measured Reflectance Versus Wavelength on Microporous Black PTFE.

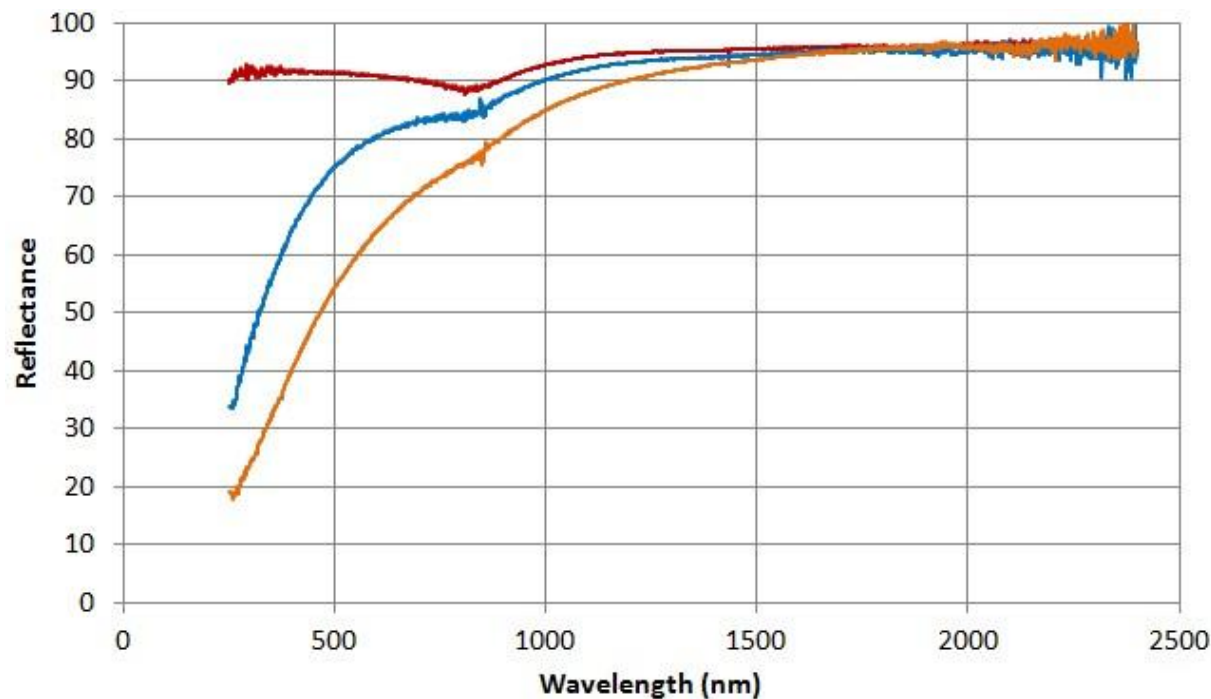

\begin{tabular}{|lll|}
\hline -initial in vac & & $\alpha=0.081$ \\
$-1.1 \mathrm{E} 16 \mathrm{p}+/ \mathrm{cm} 2(2.0 \mathrm{KeV})$ & $2.6 \mathrm{E} 16 \mathrm{e}-/ \mathrm{cm} 2(500 \mathrm{eV})$ & $\alpha=0.184$ \\
$-5.0 \mathrm{E} 16 \mathrm{p}+/ \mathrm{cm} 2(2.0 \mathrm{KeV})$ & $6.1 \mathrm{E} 16 \mathrm{e}-/ \mathrm{cm} 2(500 \mathrm{eV})$ & $\alpha=0.303$ \\
\hline
\end{tabular}

Figure 21. In-Situ Measured Reflectance Versus Wavelength on Microporous White PTFE. 


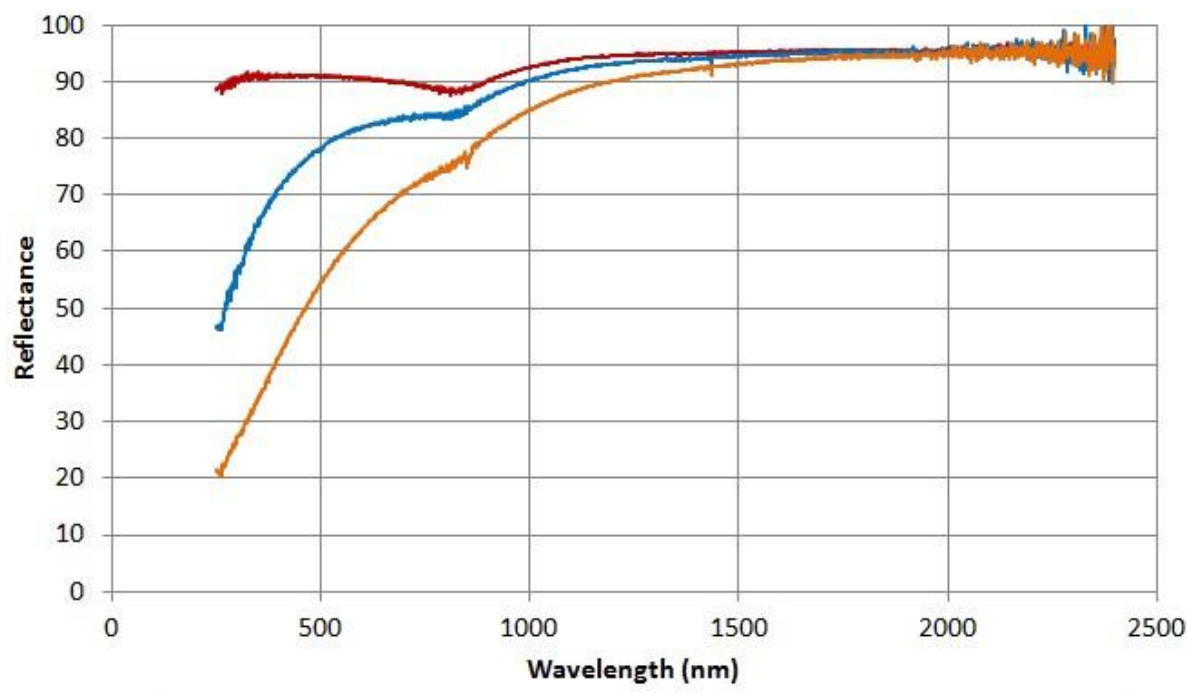

\begin{tabular}{|lll|}
\hline -initial in vac & $\alpha=0.085$ \\
$-2.4 \mathrm{E} 16 \mathrm{p}+/ \mathrm{cm} 2(2.0 \mathrm{KeV})$ & $1.4 \mathrm{E} 16 \mathrm{e}-/ \mathrm{cm} 2(10 \mathrm{KeV})$ & $\alpha=0.164$ \\
$-5.4 \mathrm{E} 16 \mathrm{p}+/ \mathrm{cm} 2(2.0 \mathrm{KeV})$ & $6.9 \mathrm{E} 16 \mathrm{e}-/ \mathrm{cm} 2(10 \mathrm{KeV})$ & $\alpha=0.301$ \\
\hline
\end{tabular}

Figure 22. In-Situ Measured Reflectance Versus Wavelength on Microporous White PTFE.

\section{TESTING ON MICROPOROUS PTFE FLIGHT BATCH}

\subsection{Thermal Vacuum Cycling on Flight Microporous PTFE Sheets}

A thermal vacuum cycling test on the flight microporous PTFE sheets was performed at GSFC. A bakeout was also performed to meet the OSIRIS-REx mission contamination control requirement after eight thermal vacuum cycles. Figure 23 shows the PTFE sheets in the vacuum chamber before pumpdown. Figure 24 shows the temperatures of the microporous black PTFE adiabatic coupons which were spread out in the vacuum chamber. Calrod heaters, a gaseous nitrogen heated chamber shroud and a gaseous nitrogen heated cold plate were used to meet the hot soak temperature requirement. The cold soak temperature requirement was met by a gaseous nitrogen cooled chamber shroud and liquid nitrogen cooled cold plate.

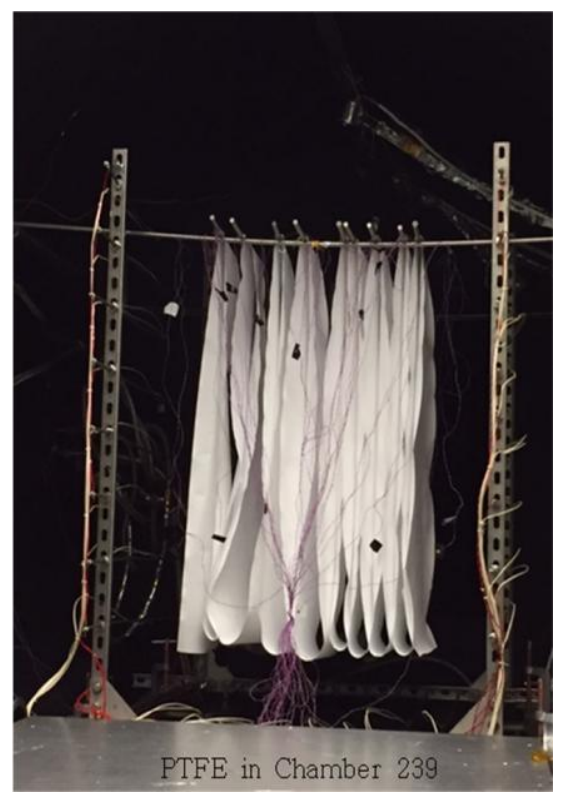

Figure 23. Microporous PTFE Sheets in Thermal Vacuum Cycling and Bakeout Test On Flight Batch. 


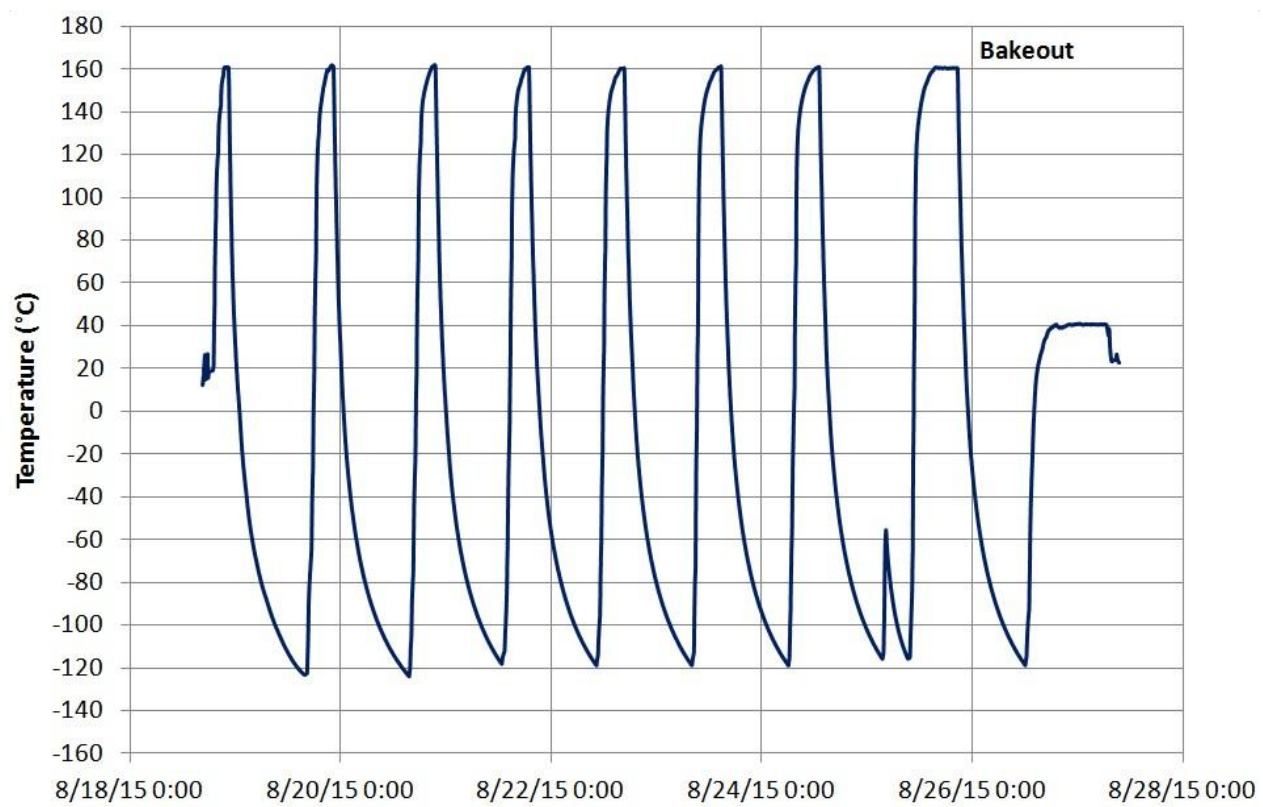

Figure 24. Average Temperature of Microporous Black PTFE Adiabatic Coupons.

\subsection{BRDF of Microporous PTFE Flight Batch After Thermal Vacuum Cycling}

After the thermal vacuum cycling test, BRDF measurements were performed on microporous black and white PTFE flight batch coupons before and after taping seams were performed. Taping seams were to simulate attaching flight microporous PTFE sheets to MLI blankets. The coupons were attached to flight-like black Kapton. Figure 25 and Figure 26 show the results of BRDF for the microporous black PTFE coupon and microporous white PTFE coupon respectively. It can be seen that microporous black PTFE meets the SamCam BRDF requirement of $0.32 \mathrm{sr}^{-1}$ with plenty of margins. In contrast, microporous white PTFE does not meet the SamCam BRDF requirement.

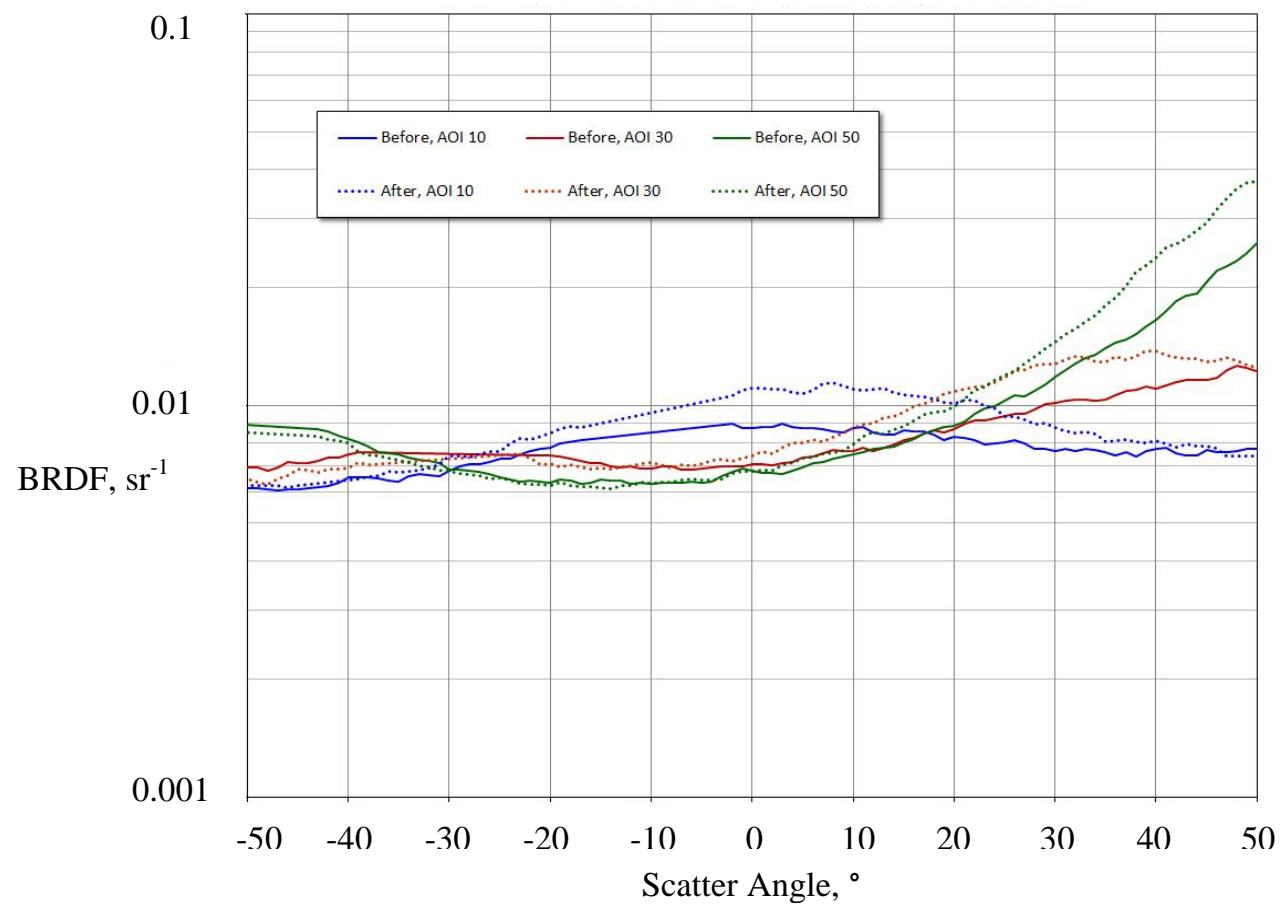

Figure 25. Microporous Black PTFE BRDF at $514 \mathrm{~nm}$ Before and after Taping Seams. 


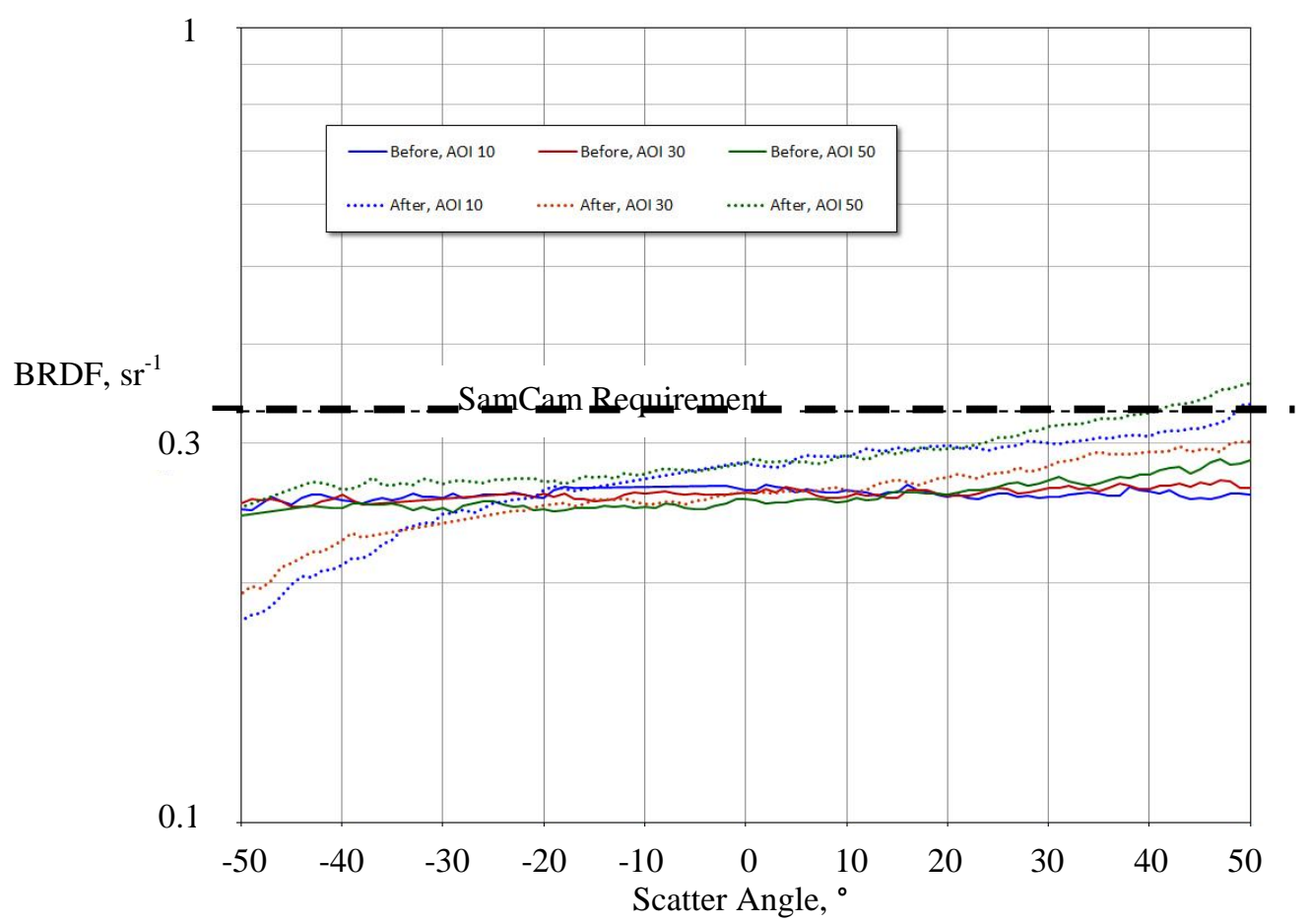

Figure 26. Microporous White PTFE BRDF at $514 \mathrm{~nm}$ before and after Taping Seams.

\subsection{Post TVAC Surface Resistivity Measurement}

The surface resistivity of microporous black PTFE flight batch coupons was measured to be $2 \times 10^{5} \mathrm{ohm} / \mathrm{square}$ in ambient pressure. It remained unchanged after three days in vacuum. It is electrically conductive and meets the $1 \times 10^{9}$ $\mathrm{ohm} /$ square OSIRIS-REx mission surface resistivity requirement. The surface resistivity of microporous white PTFE flight batch coupons was measured to be $1 \times 10^{14} \mathrm{ohm} /$ square in ambient pressure. It is electrically non-conductive and does not meet the OSIRIS-REx mission surface resistivity requirement. It needs to electrically grounded if it is used for flight in the OSIRIS-REx mission.

\subsection{Post TVAC Tape Lift and Wear Tests}

A wear test, which abrades the surfaces by applying a 2-lb force with a cheese cloth or a 5-lb force with an eraser, was performed on the microporous black and white PTFE flight batch coupons. Figure 27 shows the test results for the microporous black PTFE coupons. The abrasion caused some discoloration. Figure 28 shows the test results on the microporous white PTFE coupons. The abrasion did not cause any difference in appearance of the coupons. The wear test was followed by a tape lift test. Figures 29 and 30 show the tape lift test results. A small amount of microporous black PTFE was lifted by the tape. Nothing was lifted from the microporous white PTFE.

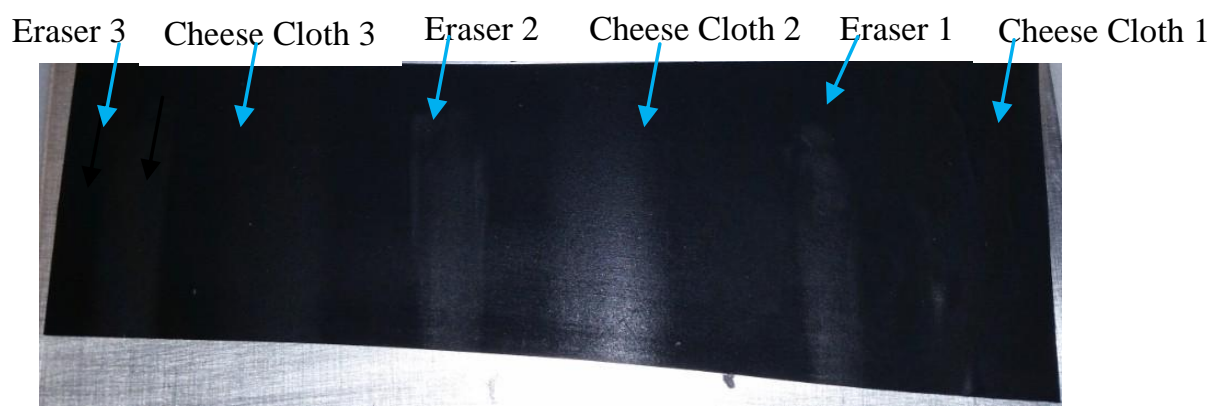

Figure 27. Results of Wear Test on Microporous Black PTFE. 


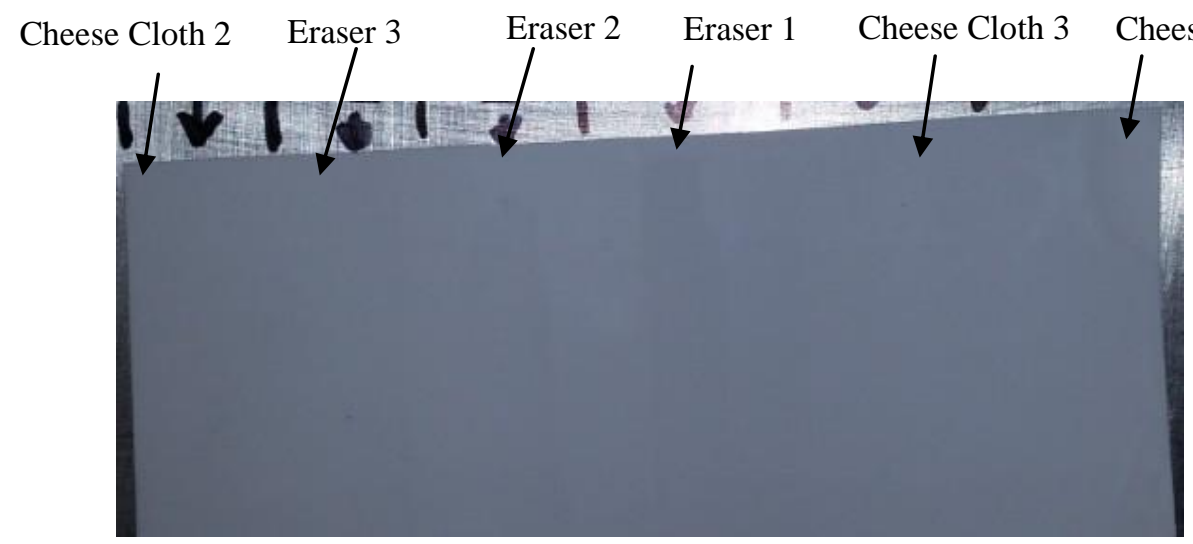

Figure 28. Results of Wear Test on Microporous White PTFE.

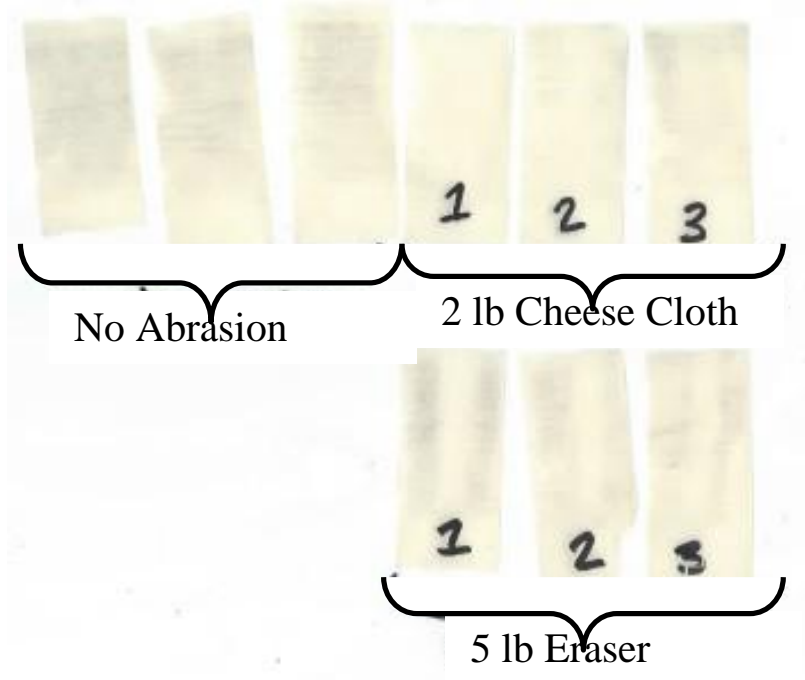

Figure 29. Results of Tape Lift Test On Microporous Black PTFE.
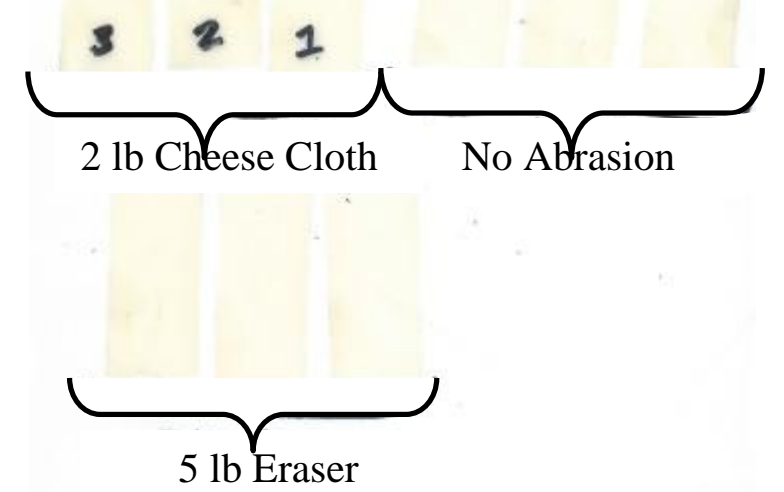

Figure 30. Results of Tape Lift Test On Microporous White PTFE. 


\subsection{Post TVAC Acoustics Fallout Test}

An acoustic fallout test was performed on microporous black and white PTFE flight batch coupons. Table 1 is a summary of the results. There was no significant fallout or material degradation during the test. The test results showed there were, but not many, PTFE particles (i.e., cleaner than Level 65). The test results for microporous white PTFE were extremely clean. Contamination control engineers analyzed both microporous black PTFE coupons. They found only two PTFE particles, which equates to Level 65, on coupon Black \#1, and no particle on coupon Black \#2.

Table 1. Acoustics Fallout Test Results.

\begin{tabular}{|c|c|c|c|c|c|c|}
\hline & $\begin{array}{c}\text { Chamber } \\
\text { Blank }\end{array}$ & White \#1 & White \#2 & White \#3 & Black \#1 & Black \#2 \\
\hline Percent Area Covered $(\%)$ & $1.84 \times 10^{-3}$ & $2.11 \times 10^{-3}$ & $3.47 \times 10^{-4}$ & $5.36 \times 10^{-5}$ & $1.98 \times 10^{-3}$ & $2.27 \times 10^{-3}$ \\
\hline Particle Size $(\mu \mathrm{m})$ & \multicolumn{7}{|c|}{ Number } \\
\hline$>250$ & 1 & 3 & 1 & 0 & 1 & 2 \\
\hline 100 to 250 & 1 & 0 & 0 & 0 & 4 & 2 \\
\hline 50 to 100 & 1 & 0 & 0 & 1 & 5 & 0 \\
\hline 25 to 50 & 2 & 0 & 1 & 0 & 9 & 3 \\
\hline 15 to 25 & 5 & 0 & 2 & 0 & 1 & 0 \\
\hline 5 to 15 & 14 & 0 & 1 & 0 & 0 & 1 \\
\hline$<5$ & 2 & 0 & 1 & 0 & 0 & 0 \\
\hline
\end{tabular}

\subsection{Post TVAC Particulate Count Test}

A particulate count test was performed on microporous PTFE flight batch coupons. It was to simulate handling and installation of microporous PTFE to full size MLI blankets. Figure 31 shows a preparation for microporous black PTFE around the harness simulator. Table 2 presents the particulate count test results. The "Drag" test involved wrapping a cable harness, which is of similar size as that on the POGO section of the TAGSAM arm, in each type of material, followed by mimicking the drag seen of the POGO harness on the grit blasted section of the arm. The "Wrap" test involved wrapping each material around a mock-up arm with a single layer of germanium black Kapton to simulate installation of microporous PTFE to the flight MLI. The cleanliness levels shown are mathematical conversions from Percent Area Covered (PAC) to provide an approximate particulate cleanliness level. The goal was to remain under Level 100. Average Max Feret is the average value of the largest dimension of the particles. Microporous black PTFE did not shed a significant number of particles. All tests show "less than background" results, except one where the sample disk was opened inadvertently.

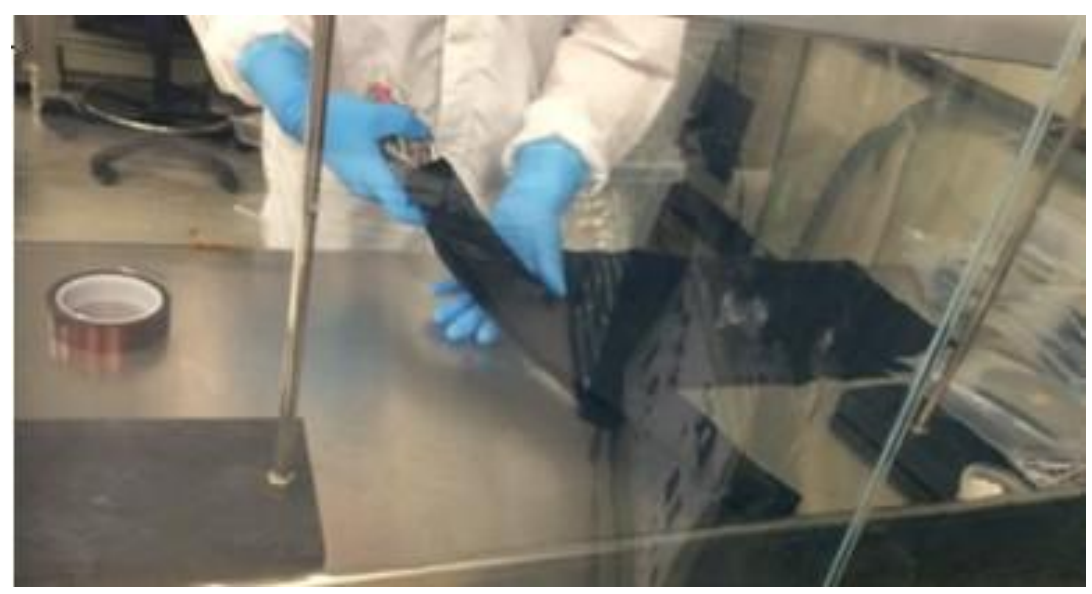

Figure 31. Preparing Microporous Black PTFE Around Harness Simulator for Particulate Count Test. 
Table 2. Particulate Count Test Results.

\begin{tabular}{|c|c|c|c|c|c|}
\hline Sample & $\operatorname{PAC}(\%)$ & $\begin{array}{c}\text { Cleanliness } \\
\text { Level } \\
\text { (Spheres) }\end{array}$ & $\begin{array}{c}\text { Number of } \\
\text { Objects } \\
\text { Counted } \\
\end{array}$ & $\begin{array}{c}\text { Average } \\
\text { Max. Feret } \\
\text { (Micron) }\end{array}$ & Notes \\
\hline White Drag Control & 0.0003 & 97 & 7 & 97 & \\
\hline White Drag \#1 & 0.00001 & 28 & 1 & 23 & \\
\hline White Drag \#2 & 0.0007 & 126 & 9 & 116 & \\
\hline White Drag \#3 & 0.000002 & 18 & 1 & 21 & \\
\hline White Wrap Control & 0.0005 & 114 & 13 & 77 & \\
\hline White Wrap \#1 & 0.0001 & 63 & 6 & 19 & \\
\hline White Wrap \#2 & 0.0001 & 63 & 4 & 24 & \\
\hline White Wrap \#3 & 0.0001 & 62 & 3 & 26 & \\
\hline Black Drag Control & 0.0002 & 88 & 4 & 156 & \\
\hline Black Drag \#1 & 0.002 & 163 & 58 & 29 & $*$ \\
\hline Black Drag \#2 & 0.00004 & 55 & 3 & 77 & \\
\hline Black Drag \#3 & 0.0002 & 85 & 14 & 58 & \\
\hline Black Wrap Control & 0.0001 & 76 & 4 & 76 & \\
\hline Black Wrap \#1 & 0.0001 & 66 & 6 & 54 & \\
\hline Black Wrap \#2 & 0.00003 & 49 & 13 & 14 & \\
\hline Black Wrap \#3 & 0.0001 & 71 & 7 & 40 & \\
\hline
\end{tabular}

*Wafer case opened during transport to be analyzed

\subsection{Post TVAC Rip/Tear Test}

A rip/tear test was performed across a $0.3 \mathrm{~m}(1 \mathrm{ft})$ wide sheet of microporous black PTFE flight batch. Its objective was to see if rip or tear on the microporous PTFE will generate particles. The results of the test showed that the risk of generating particles by rip or tear is low.

\section{INTEGRATION OF MICROPOROUS PTFE TO OSIRIS-REX FLIGHT HARDWARE}

Based on the results of testing above, microporous black PTFE was selected for flight use in the OSIRIS-REx mission. It has been installed to the TAGSAM MLI (Figure 32), PolyCam sunshade MLI (Figure 33) and Sam motor riser MLI (Figure 33). A high temperature acrylic adhesive is used. Imaging performed on the ground verified that it optically satisfies the SamCam.

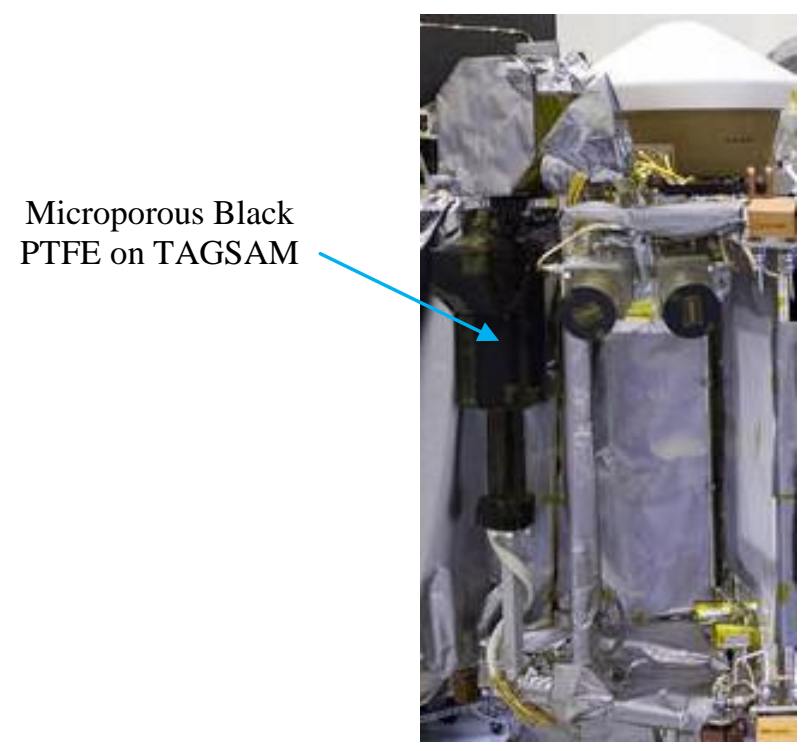

Figure 32. Microporous Black PTFE Cover Installed to TAGSAM MLI. 


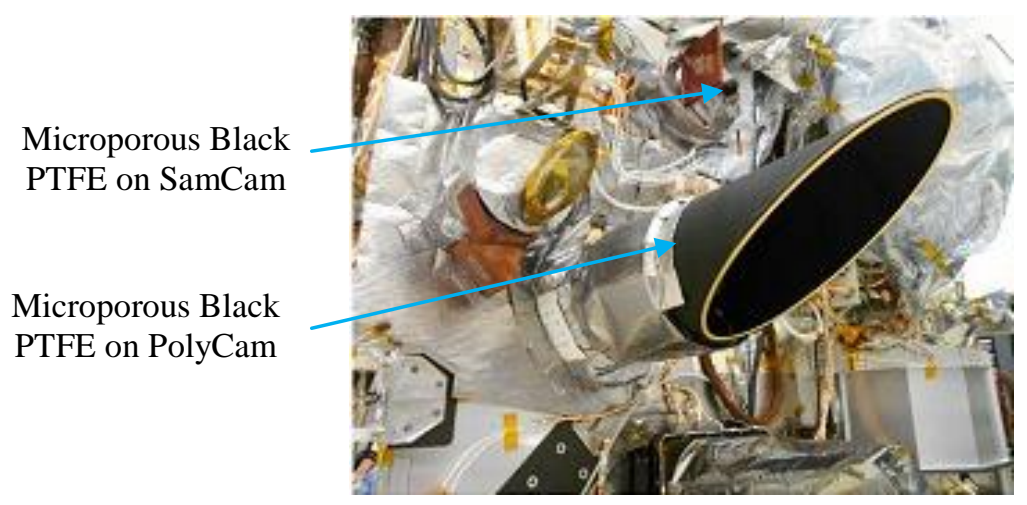

Figure 33. Microporous Black PTFE Cover Installed to PolyCam Sunshade MLI and SamCam Motor Riser MLI.

\section{CONCLUSION}

An innovative design of using microporous PTFE thin sheets as a solar diffuser for MLI blankets or mechanical structure has been has been developed. Microporous black PTFE and white PTFE thin sheets, with a $0.254 \mathrm{~mm}$ (10-mil) thickness, have been qualified for flight at NASA GSFC. Microporous black PTFE thin sheets meet the OSIRIS-REx SamCam BRDF requirement with plenty of margins. Its contamination concern is low despite it is non-zero. It is expected to give the best images for SamCam and is the best overall choice. Microporous white PTFE has zero contamination concern, but does not meet the SamCam BRDF requirement. It may bloom the SamCam image. Therefore, microporous black PTFE thin sheet was selected for OSIRIS-REx flight use. It has been installed to the TAGSAM MLI, PolyCam sunshade MLI and SamCam motor riser MLI. Results of imaging on the ground after the flight system TVAC test verified that it satisfies the SamCam optical requirement.

\section{REFERENCES}

[1] Kato, D., "Structures, A3 - Configuration Overview", OSIRIS-REx Structures and Mechanisms CDR, LMSSC, Jan. 20-21, 2014.

[2] Linn, T., et al., "TAGSAM, 1_2 - TAG Event Summary", OSIRIS-REx SARA/TAGSAM/SRC CDR, LMSSC, Feb. 3-6, 2014.

[3] Sutter, B., "Possible Sun Angles During TAG vs. Latitude on Asteroid", Lockheed Martin, email to OCAMS team on Feb. 13, 2014.

[4] D’Aubigny, C. and Pfisterer R., "SamCam TAGSAM Glint Evaluation", Univ. of Arizona, 18 June 2014.

[5] Tveekrem, J., "Sun Glint into SamCam from TAGSAM Wrist MLI, Rev. 1", OSIRIS-REx Project, GSFC, Sept. 12, 2015.

[6] Tsai, B. K., et al., "A Comparison of Optical Properties between High Density and Low Density Sintered PTFE", Proc. of SPIE Vol. 7065, 70650Y, (2008).

[7] Helmlinger, M. and Arecchi A., "Space Grade Spectralon", CalCon, Aug. 28, 2012.

[8] Springsteen, A., et al., "Sphere Coatings- A Historical Perspective", Workshop on Photometry and Colorimetry for Solid State Lighting, 2009.

[9] http://www.aviantechnologies.com/, Avian Technologies, LLC, 2015.

[10] Georgiev, G. T. and Butler, J. J., "Long-Term Calibration Study Of Gray-Scale Spectralon Diffusers", IGARSS 2009, Paper no. 2834.

[11] Stiegman, A. E., et al., "Ultraviolet stability and contamination analysis of Spectralon diffuse reflectance material", Optical Engineering 32(4), 799-804 (Apr. 1993).

[12] Frouin, R., ed., "In-flight Calibration of Satellite Ocean-Color Sensors", IOCCG Report Number 14, 2013.

[13] Bruegge, C. J., "Use of Spectralon as a diffuse reflectance standard for in-flight calibration of earth-orbiting sensors", Optical Engineering 32(4), Apr. 1993.

[14] "Zenith Lite ${ }^{\mathrm{TM}}$ Targets - Diffuse Reflectance, High Durability, Lightweight", Sphere Optics, Jan. 2015. 
[15] "Zenith Polymer® Diffuse Reflectance Standards, Targets and Materials - For Use Over The UV, VIS and NIR Spectral Regions", Sphere Optics, Jan. 2012.

[16]"Space-Grade Spectralon ${ }^{\circledR}$ Reflectance Material - Diffuse reflectance material designed for space applications", Labsphere Inc., 2015.

[17] Messenger, S., et al., "Contamination Knowledge Report 6, PTFE FESEM and L2MS Analysis", August 7, 2015. 